


\title{
Mimetic Dominance and the Economics of Exclusion: Private Goods in Public Context
}

\author{
Alex Imas (University of Chicago) and Kristóf Madarász (LSE)*
}

December 16, 2020

\begin{abstract}
We propose that a person's valuation from consuming an object or possessing an attribute is increasing in others' unmet excess desire for it. Such mimetic dominance-seeking helps explain a host of market anomalies and generates novel predictions in a variety of domains. In bilateral exchange, there is a reluctance to trade, and people exhibit a 'social' endowment effect. The value of consuming a good increases in its scarcity, which generates a motive for exclusion. Randomly excluding potential consumers from the opportunity to acquire a product will increase profits for a classic monopolist producing at zero marginal cost and a seller's rents in first-price auctions. We test the predictions of the model empirically. When auctioning a private good, all else equal, randomly excluding people from the opportunity to bid substantially increases bids amongst those who retain this option. Exclusion leads to bigger gains in expected revenue than increasing competition through inclusion. Such effects are absent when those excluded are known to have lower valuations. In basic exchange, a person's willingness to pay for a good increases substantially when others are excluded from the opportunity of buying the same kind of good. Mimetic preferences have implications for both non-price and price based methods of exclusion: the model generates 'Veblen effects,' rationalizes attitudes against redistribution, immigration, and trade, and provides a novel motive for social stratification and discrimination.
\end{abstract}

Keywords: Mimetic Preferences, Objects of Desire, Exclusion, Trade, Auctions, Competition, Inequality

\footnotetext{
${ }^{*}$ We are grateful to Nageeb Ali, Sylvain Chassang, James Choi, Stefano Della Vigna, Dan Gilbert, Shengwu Li, George Loewenstein, Theo Offerman, Ryan Oprea, Pietro Ortoleva, Wolfgang Pesendorfer, Klara Steinitz, Adam Szeidl, Leeat Yariv, and, in particular, Roland Benabou for discussions. We also thank seminar audiences at CEU, Chicago Booth, Carnegie Mellon, Harvard, Hong Kong, LSE, Princeton, Peking University HSBC Business School, VIBES June 8, 2020, and the 2019 Warwick-Princeton Conference on Political Economy in Venice. All errors are our own. Contact: alex.imas@chicagobooth.edu or k.p.madarasz@lse.ac.uk
} 


\section{Introduction}

"Self-love (amour de soi), which regards only ourselves, is contented when our true needs are satisfied. But amour-propre, which makes comparisons, is never content and never could be, because this sentiment, preferring ourselves to others, also demands others to prefer us to themselves, which is impossible. This is how the gentle and affectionate passions are born of self-love (amour de soi), and how the hateful and irascible passions are born of amour-propre." — Jean-Jacques Rousseau, Emile or On Education, 1762.

"Of all the passions, the passion for the Inner Ring is most skillful in making a man who is not yet a very bad man do very bad things. But your genuine Inner Ring exists for exclusion. There'd be no fun if there were no outsiders. The invisible line would have no meaning unless most people were on the wrong side of it. Exclusion is no accident; it is the essence." - C.S. Lewis, The Inner Ring, 1944.

"Andrea: But what if this isn't what I want? I mean, what if I don't wanna live the way you live? Miranda: Oh, don't be ridiculous, Andrea. Everybody wants this. Everybody wants to be us." — The Devil Wears Prada, 2006.

The value a person attaches to an object is often determined not only by her intrinsic taste but by aspects of social comparison as well. In this paper we argue that one's desire for an object is linked to the desires of others, in that her pleasure from consuming a good or possessing an attribute is increasing in others' unmet intrinsic taste for the same object. We depart from the premise that desires are autonomous and instead link them to a form of dominance-seeking, whereby the lack that others experience by not having one's object boosts the possessor's value from keeping and consuming it. To illustrate, consider a fable on the rivalry between two siblings Luluwa and Awan. No matter how many toys they have at home, there is always the one that each child wants to play with - the toy that the other child is playing with. She wants to take this toy away and play with it herself. ${ }^{1}$

We formally develop a model of such mimetic dominance-seeking, and empirically demonstrate its influence in several economically-important environments including basic exchange. ${ }^{2}$ Mimetic preferences lead to a reluctance to trade and a direct preference for objects that become more scarce. The latter generates a motive for exclusion: all else equal, a person derives more utility from the consumption of a good or the possession of an attribute if she knows that others would also like to consume it, but cannot.

\footnotetext{
${ }^{1}$ According to some traditions, Luluwa and Awan were the partners and sisters of Cain and Abel.

${ }^{2}$ We use the term mimetic to refer to the fact that one person's (unmet) desires are mirrored in the preferences of another.
} 
Mimetic dominance-seeking helps rationalize seemingly anomalous attitudes towards exclusionary policies, as well as properties of markets and institutions that employ social exclusion as a tool for rent-seeking.

Two experiments provide direct support for the model while ruling out a host of alternative explanations. In non-competitive exchange, we find that people's willingness to pay for a private good increases substantially when others are explicitly barred from the opportunity of buying the same kind of good. When competing for a single good through a first-price auction, we find that randomly excluding potential bidders leads to substantially higher bids and revenue than when selling the good under full inclusion. Moreover, random exclusion leads to more aggressive bidding than increasing competition under full inclusion - on the margin, the increase in average bids due to exclusion is nearly double the effect of increasing competition.

While to the best of our knowledge such mimetic preferences have not been considered explicitly in economics, the idea that dominance or superiority-seeking is an important aspect of social interactions has a long tradition. Scholars such as St. Augustine (426), Hobbes (1658), and Rousseau (1755) have discussed analogous motives when describing aspects of human sociability as key for determining the function, and dysfunction, of political institutions. ${ }^{3}$ For example, in his Discourse on the Origin of Inequality, Rousseau emphasizes the role of what he considers to be the critical and potentially destructive motive of human sociability: a person's tendency to compare herself to others and engage in activities whereby she can experience her superiority over them. Such amour propre, as Rousseau calls it, represents a person's concern with comparative success or failure as a social being and involves joy from feeling superior over others. He argues that this motive emerges in groups and contrasts it with the motive of amour de soi (self interest). In Rousseau's account, while the latter is a centripetal force which compels people to come together and form associations to benefit from the utility of exchange, the former emerges in such groups as a rival centrifugal force which can then rip such associations apart and requires political institutions to manage. More recently, Dr. Martin Luther King Jr. referred to a similar motive as a universal 'Drum Major Instinct.'

We argue that economic contexts naturally generate such dominance seeking over the unmet desires of other. Our formulation also draws on the work of the literary scholar René Girard (1966, 2002) who emphasizes a distinction between appetitesconsumption utility in our context - and more intense desires. In his language, appetites are basic and individual. Desires, on the other hand, are not autonomous but inherently mimetic. It is when a person recognizes an other's appetite for the same object that

\footnotetext{
${ }^{3}$ See also, e.g., Hirschman (1979) or Hont (2015).

${ }^{4}$ Dr. King's sermon can be found here: https://kinginstitute.stanford.edu/kingpapers/documents/drum-major-instinct-sermon-delivered-ebenezer-baptist-church.
} 
her more intense desire for this object is formed.

In our model, person $i$ 's utility from consuming an object is the sum of her private consumption utility (intrinsic taste) from this object, and a comparative term representing the mimetic dominance motive. This corresponds to the difference between the maximal unsatisfied consumption utility of others for the object: the largest gain in consumption utility that another individual in $i$ 's social context would experience if it was he who consumed the object instead of her. This comparative term is mimetic: a person's valuation of an object mirrors others' intrinsic taste for it. It involves dominance because the boost in the valuation of the object is derived from someone else's unmet excess taste for it. In turn, people have a greater demand for goods that others want more but do not have. By developing a portable structure to this idea, our framework facilitates the study of its implications for competition, exchange, and political economy.

We first consider non-competitive settings. In bilateral trade, because owners value the unmet desire of potential buyers, mimetic preferences lead to a reluctance to trade and a gap between a seller's willingness to accept and a buyer's willingness to sell, i.e. a 'social' endowment effect (Kahneman et al., 1990). This endowment effect is social in the sense that it depends on the owner's beliefs about the desires of others and thus also on the mechanism of trade. Mimetic dominance also implies a direct preference for objects that are relatively more scarce. People enjoy keeping and consuming a good more the greater is the unmet excess desire of others. This generates a preference for exclusion which can be exploited by firms as a tool for rent-seeking. In the context of the classic monopolist selling identical copies to a pool of ex-ante identical consumers at zero marginal cost, relative to the classic optimal mechanism of charging a common price to all potential buyers, the monopolist always benefits from randomly excluding a limited fraction of the potential buyers and denying them access to purchasing the good. As outlined in Section 5, such exclusion based on arbitrary characteristics is commonly employed by firms as in the case of artificially restricting supply and in advertising through the use of scarcity marketing.

We then proceed to derive the implications of mimetic dominance-seeking for competitive exchange. We show that randomly excluding potential buyers may lead to both higher bids and higher revenue for a seller of a private good via a first-price auction. Holding constant the number of people randomly excluded from the opportunity to compete, a larger number of active bidders leads to higher average bids and revenuethe standard competitive force is still present. Importantly, with mimetic preferences, holding the number of active bidders constant, a larger number of excluded bidders also leads to higher bids and revenue. Random exclusion of some of the potential buyers increases the chance that an excluded person may have greater desire for the 
item than the prospective winner of the auction, which boosts the latter's valuation from obtaining the object. We specify conditions under which, in stark contrast to the standard competitive force, excluding bidders from a given pool not only increases bids but also the seller's expected revenue. Furthermore, if the extent of mimetic dominance seeking is sufficiently high, limiting competition through random exclusion may also generate higher rents for the seller than employing a reserve price but allowing everyone to bid-the classic optimal mechanism for selling a private good.

Our first experimental study tested the predictions for first-price auctions. ${ }^{5}$ In this study, participants report their bids for a unique good - a custom T-shirt designed specifically for the experiment - in one of three main treatments. In the Baseline treatment, all $M$ potential bidders participated in the auction. In the Random Exclusion treatment, $K$ subjects were randomly excluded from the opportunity to submit a bid from the start; only the remaining $M-K$ individuals submitted bids for the item. Each participant was aware of the total group size $M$, the number excluded $K$, and that exclusion was randomly determined. To rule out alternative explanations, we ran a third treatment in which participants were similarly excluded from the opportunity to bid, but the exclusion was not random. In this Non-Random Exclusion treatment, before the auction was announced, each individual first saw the item and used a scale to indicate how much they would like to own it. Participants' answers were then used to determine who was excluded from the auction: when announcing the exclusion procedure, the experimenter highlighted that the excluded participants reported the lowest desire for the good (without disclosing their scores). Note that in this treatment, exclusion per se is the same as in the Random Exclusion treatment-only $M-K$ bidders had the opportunity to attain the good-but those who had this opportunity knew that the desire of those excluded was lower than their own.

We first confirm the prediction that in the Baseline treatment the average bids and expected revenue increase with greater competition, i.e., with the group size $M$ : increasing the group size leads to an increase in both the average bids and expected revenue of the seller. This behavioral response provides credence to the validity of the paradigm. However, consistent with the predictions of mimetic dominance, random exclusion spurs more aggressive bidding and increases the seller's expected revenue relative to the Baseline condition. The increase in average bids due to exclusion is substantially larger than the impact of increasing competition. For example, the average bids from a group of four active bidders with exclusion - where two are randomly excluded from a group of six $(M=6$ and $K=2)$-were nearly $60 \%$ higher than the average bids from a group of six active bidders without exclusion $(M=6$ and $K=0)$. Holding the number of active bidders constant, we also find that the presence of exclu-

${ }^{5}$ For a recent review of prior studies using this format, see Kagel and Levin (2014). 
sion significantly increases bids and expected revenue. The average bids from a group of four active bidders with exclusion, $(M=6$ and $K=2)$, is almost double the average bids from a group of four active bidders without exclusion $(M=4$ and $K=0)$.

Compared to Random Exclusion, mimetic dominance motives are predicted to be muted in the Non-Random Exclusion treatment since bidders know that those who lack the opportunity to obtain the good also desire it less than they do. Furthermore, in the absence of mimetic dominance-seeking, the average bids and the sellers' expected revenues should be higher in this treatment than under random exclusion since bidders now come from a positively-selected pool. This makes the Non-Random Exclusion treatment a conservative test for whether the results of the Random Exclusion treatment were driven by mimetic preferences or due to exclusion per se. In the case of the latter, one would expect even higher average bids under Non-Random Exclusion compared to Baseline. In contrast to this alternative explanation but consistent with our setup, average bids and expected revenue in the Non-Random Exclusion treatment were similar to those the Baseline treatment. This muted effect points to mimetic dominance, as opposed to experimental artifacts, as the driver of increased bids in the Random Exclusion treatment.

Our second experiment was designed to directly test the implications of mimetic dominance motives in a simple non-competitive setting. While the results of the first experiment are consistent with mimetic preferences, they do not pin down whether the results are driven my mimetic dominance versus mimetic desire without an exclusionary motive. In the case of mimetic desire, a person would derive greater utility from the knowledge that others desire the item more than she does irrespective of whether their desire is met or not. In our second study, participants reported their maximum willingness to pay (WTP) for a unique good (a custom T-shirt) in one of two treatments. ${ }^{6}$ In the Baseline treatment, all $M$ participants in a group could privately submit their bid for the good. In the Random Exclusion treatment, the experimenter publicly announced the random exclusion of $K$ subjects from the opportunity to purchase the good, allowing only the remaining $M-K$ participants to privately submit their bids. As in the first study, each participant was aware of the total group size $M$, the number excluded $K$, and that the exclusion process was random and not due to the actual scarcity of the item. In line with the predictions of the proposed framework, randomly barring participants from the opportunity to acquire the good led to a nearly $50 \%$ increase in the WTP for the good.

We then use structural estimation to measure the extent of mimetic dominance-

\footnotetext{
${ }^{6}$ We employed an incentive compatible mechanism to elicit participants' WTP for the good. A common price was randomly drawn for each session. If a participant's bid was greater than this price, then she would pay the price and obtain the good; if her bid was smaller than the price, she would not get the good and pay nothing.
} 
seeking in the second study. Estimates provide further support for the theory: the weight placed on mimetic dominance is high, which rationalizes the findings from the first study where sellers' rents are increasing in the number of excluded market participants.

Together the two experiments provide support for the mimetic dominance motive while ruling out alternative explanations. Because the supply of the good remains constant across all treatments in the auction setting - only one individual is able to obtain the product - this rules out exclusion as a signal of underlying value or scarcity of the object. For the same reason, direct consumption externalities or classic social preferences cannot rationalize the findings. The basic exchange setting allows us to further differentiate between simple mimetic desire and mimetic dominance. The results also rule out informational effects linked to interdependent values without an exclusionary motive more generally, e.g., à la Milgrom and Weber (1982), as drivers of our results. If the results were somehow due to mimetic desire or such interdependent values, then bids in the basic exchange experiment should only depend on $M$ and not on $K$-we should observe no differences in bids between the Baseline and Random Exclusion treatments. Instead we find that WTP increases substantially.

We argue that the impact of mimetic dominance-seeking on behavior is relevant in many economic contexts, and that this motive offers a parsimonious explanation for seemingly anomalous methods of exclusion employed by firms and institutions. In Section 5, we outline broader implications for the use of non-price-based and priced-based methods of exclusion. In the presence of heterogeneous income, price-based exclusion leads to so-called 'Veblen effects' (Veblen, 1899), where the demand for luxury goods increases in response to price increases. This seeming violation of the law of demand has typically been explained through the motive of signaling one's income status. ${ }^{7}$ Mimetic dominance provides an alternative and complementary mechanism which operates irrespective of the direct observability of income status or consumption. To see the intuition, take a setting with rich and poor consumers and identical taste distributions. Poor consumers face a tighter budget constraint. By raising the price above the budget constraint, demand of the rich increases because the maximal unsatisfied consumption utility for the object goes up. This increases the demand of the latter group, allowing the firm to extract profit. As we discuss further in Section 5, the predictions of mimetic dominance for generating Veblen effects closely match the consumer landscape.

The use of non-price methods to artificially restrict availability of products and services is common in a variety of domains. Advertising often exploits the psychology of exclusion in sales of private goods. The use of scarcity marketing is one of the cornerstones of advertising practice. In his runaway bestseller on the topic, titled

${ }^{7}$ See, for example, Pesendorfer (1995) and Bagwell and Bernheim (1996). 
Influence: The Psychology of Persuasion, Robert Cialdini identifies scarcity marketing as one of the six 'Weapons of Influence.' He argues that scarcity marketing is most effective when people are made to believe that rivalrous others are simultaneously competing for the same good - that attaining it means others who want the good cannot have it. Many advertising guides explicitly note that the practice of scarcity marketing rests on the premise that access to exclusive goods makes owners 'feel powerful' as a result of obtaining something that others crave but can't have. ${ }^{8}$ In a similar vein, Becker (1991) examines the lack of firm response to excess demand, highlighting the puzzling presence of long queues for products such as new phone models, restaurants, nightclubs, and sporting events. He considers several explanations, but ultimately concludes that they would not generate the unwillingness of firms to either expand supply or raise the price. In our setting, firms and advertisers may artificially restrict actual or perceived availability of a good so that those who end up attaining it get a utility boost from the unmet desires of others. Thus the gap between supply and demand is an intentional tool to extract rents from consumers - exclusion is a feature rather than a bug - with firms being aware of the fact that increasing supply may actually lead to a drop in demand.

The quest for mimetic dominance also has broad implications for political economy, offering a rationale for people's attitudes in favor of exclusionary policies and providing a novel mechanism for group-based discrimination. 'Included' members derive greater pleasure from consuming goods, possessing attributes, or belonging to organizations with some attractive features from which others are restricted - even if these restrictions are unnecessary from a marginal cost perspective (e.g., in case of 'club goods,' which are non-rivalrous on the margin), lead to material losses (e.g., in the case of immigration restrictions and protectionism), and are based on seemingly arbitrary criteria. Mimetic dominance-seeking also rationalizes seemingly anomalous attitudes towards redistributive policies, such as the observation that the strongest opposition to increases in the minimum wage is concentrated amongst those making the secondto-lowest amount (Kuziemko et al., 2014), and provides a psychological basis for the maintenance of social stratification (Darity et al., 2015). In Section 6, we also discuss how mimetic dominance can intensify what appears to be moral behavior, but through a channel distinct from those considered in the social preferences literature.

\footnotetext{
${ }^{8}$ See practical guides to marketing: https://sumo.com/stories/scarcity-marketing, https://blog.crobox.com/article/scarcity
} 


\section{Mimetic Preferences}

\section{$2.1 \quad$ Setup}

In this Section, we develop our basic model of mimetic dominance-seeking and outline some of its consequences. To illustrate, suppose first that there is a single object and two people $i$ and $j$. Let their consumption utilities (intrinsic tastes) from the object be $v_{i}$ and $v_{j}$, respectively. Person $i$ 's overall utility from consuming the good is then given by:

$$
\text { person } i \text { 's valuation }=\overbrace{v_{i}}^{\text {consumption utility }}+\alpha \overbrace{\max _{m \in\{i, j\}}\left\{v_{m}-v_{i}\right\}}^{\text {mimetic dominance }}
$$

where $\alpha \in[0,1)$ is the strength of the mimetic dominance motive. The case where $\alpha=0$ corresponds to the case of only classic consumption utility. The case where $\alpha>0$ captures the additional presence of the mimetic dominance motive: person $i$ enjoys a boost in her valuation of consuming the good proportional to the extent that $j$ derives greater consumption utility from the object than she does. If $i$ has a greater intrinsic taste for the object, this term is zero; otherwise, it is positive. Her overall desire for consuming the object mirrors $j$ 's unmet intrinsic taste for it to the extent that it is in excess of her own.

Consider now a more general setting. Let there be $M$ people. Suppose that each person $i$ 's consumption is given by a positive $L$-dimensional vector, $c_{i} \in C_{i} \subseteq \mathbb{R}^{+L}$, where each dimension corresponds to an attribute or type of good. Direct consumption utility for person $i$ is given by $V_{i}\left(c_{i}, t_{i}\right)=\sum_{l} v_{i, l}\left(c_{i, l}\right)+t_{i}$, where $t_{i} \in \mathbb{R}$ is $i$ 's monetary transfer and utility is thus quasi-linear in money. We assume that each $v_{i, l}: \mathbb{R} \rightarrow \mathbb{R}$ is increasing and bounded with $v_{i, k}(0)=0$. Let $C$ then be the product of the individual $C_{i}$ sets with generic element $c$. Person $i$ 's utility, $U_{i}\left(c, t_{i}\right): C \times \mathbb{R} \rightarrow \mathbb{R}$, is given by:

$$
V_{i}\left(c_{i}, t_{i}\right)+\alpha \sum_{l} \max _{m \in M \backslash i}\left\{v_{m, l}\left(c_{m, l}+c_{i, l}\right)-v_{m, l}\left(c_{m, l}\right)-v_{i, l}\left(c_{i, l}\right), 0\right\}
$$

In words, in addition to her standard consumption utility, a person $i$ derives utility from mimetic dominance. For each kind of good or attribute, this boost corresponds to the maximal consumption utility gain that another person $j$ would derive if he had, in additional to his own consumption, $i$ 's consumption of this good transferred to him as well-compared to the direct consumption utility $i$ derives from her consumption of this good. If person $i$ derives more consumption utility from the good than would anyone else (in addition to what they already consume), then the boost from mimetic dominance is zero; otherwise it is positive. ${ }^{9}$ A few remarks are in order.

\footnotetext{
${ }^{9}$ Our formulation implies no mimetic dominance motive over money per se, as it enters in a homogeneous quasi-linear fashion. We view this as a common simplifying assumption that is appropriate for smaller purchases.
} 
Remark 1. In our formulation, the mimetic dominance motive is evaluated attribute by attribute. It is evaluated as a consumption portfolio vis-à-vis a maximal other along each attribute. If there is only a single consumption dimension, it is with respect to a single other in one's social context. Who that person is depends endogenously on the allocation of consumption; it potentially changes as the allocation of consumption changes. When consumption utility exhibits multiple attributes, the same holds per attribute. In most settings we study, considering a single versus multiple dimensions of consumption is inconsequential for the results; in turn, these predictions do not depend on adopting an additively-separable specification of consumption utility. ${ }^{10}$

Remark 2. Mimetic dominance does not simply correspond to imitative or 'mimetic' desire, the latter referring to a motive whereby one's utility from a good is increasing in how much others like such a good irrespective of whether or not their consumption utility is satisfied. The extra utility from consuming an object in our setup does not derive from the fact that many like such a good as well. Rather, the utility boost is derived from the unmet intrinsic tastes of others. It corresponds to a motive whereby one's utility from consuming a good is increasing in the additional consumption utility that others would derive from this good if they obtained it.

Mimetic dominance seeking is also distinct from the idea of envy as is commonly expressed in the context of envy-free allocations, e.g., Varian (1976). ${ }^{11}$ There, envy refers to a person preferring what someone else has over her own allocation. It relates to what $i$ desires as a function of what $j$ has. The motive of mimetic dominance-seeking instead refers to what the other $j$ desires in relation to what $i$ has. In our setting, a person imitates the intrinsic tastes of others in her social context and derives utility from consuming an object or possessing an attribute that others crave more but do not have. Her utility is boosted through exclusion and excess.

Remark 3. A primitive of our model is the comparison set $M$. In some applications, the comparison set arises naturally given the set of people one directly interacts with: one's set of siblings, high school class, set of business partners or colleagues, sets of peers, or known social media contacts, etc. As most approaches to modeling social preferences, we do not endogenize the comparison set, but implicitly assume that such preferences are framed somewhat more narrowly and need not be global. ${ }^{12}$

Remark 4. Our formulation is purposefully simple. It puts positive weight on the

${ }^{10}$ Considering an additively-separable specification of consumption utility is a standard assumption in leading models of consumption with a comparison point, e.g., Koszegi and Rabin (2006), Bordalo, Gennaioli, and Shleifer (2013).

${ }^{11}$ See also Banerjee (1990).

${ }^{12}$ The social context that defines a comparison or consideration set, and the corresponding narrow framing, is a basic assumption in virtually all models of social preferences. Section 5 discusses how such comparison sets may be shaped in the context of political economy. Future research can investigate heterogeneity in people's social contexts and how consumers' comparison sets may be influenced by, for example, firms' or politicians' marketing campaigns. 
maximal excess desire for what one has in her social context. This parsimonious formulation is sufficient for the purposes of our paper and provides a formal way of capturing the general motive we propose. A simple alternative which may prove useful in some settings is to assume that the mimetic dominance motive is further intensified by the fraction of people in one's context with an excess intrinsic taste for what she possesses. Such an assumption will only reinforce our qualitative results. Our approach can be extended by considering more general convex functions of the unmet consumption utility of others. Future research can examine the extent to which our conclusions are robust to such generalizations.

We also do not claim that mimetic dominance applies to all goods and attributes equally — it may be affected by focus or salience (Bordalo, Gennaioli, and Shleifer, 2013; Koszegi and Szeidl, 2013), and there may be factors that mitigate its impact or shift it from one domain to another. Our formulation potentially allows for this type of heterogeneity. Understanding these factors is clearly important. We are unaware of any prior empirical research that would help guide these modelling choices and leave such extensions to future work.

Remark 5. An implication of mimetic dominance-seeking is that the valuation a person attaches to an object is dependent on her beliefs about how much others crave it. Furthermore, her willingness to trade an object is no longer independent from whom the object is sold to - a person may have a different reservation price depending on the endowment of the potential recipient as well as on the endowments of those unaffected by trade. As demonstrated in the next subsections, this generates unique predictions for a 'social' status quo bias and endowment effect, as well as a demand for scarce items.

\subsection{Trade}

We now first turn to basic implications of our setup for bilateral trade. Let there be two people, $M=2$, and a single good. The good is initially allocated randomly to one of the parties. Suppose then that each party's consumption utility is drawn i.i.d. from a strictly increasing and continuous cdf $F(v)$ defined on some bounded interval $[0, \bar{v}]$.

First, let there be no private information about preferences, i.e., the realizations of the consumption utilities become public before trade. Suppose that any monetary transfer is possible and the parties bargain efficiently. Our first corollary shows that mimetic dominance-seeking is a force against bilateral trade.

Corollary 1. If $\alpha=0$, trade happens with an ex-ante probability of $1 / 2$. If $\alpha=1$, trade never happens. For any transaction cost $\varepsilon>0$, the ex-ante probability of trade is strictly decreasing in $\alpha$. 
The logic of why trade never happens under full mimetic dominance is simple. If a person were to sell the object to the buyer, then whatever is the buyer's gain from the trade in terms of consumption utility is mirrored directly in the seller's loss of mimetic dominance. Trade is effectively zero sum. More generally, if person $j$ were to gain more in consumption utility than $i$ would lose - the very precondition of trade $-\alpha$ fraction of this would correspond to a psychological loss for $i$. Given any positive transaction cost, the ex-ante probability of trade then strictly decreases in mimetic dominance and becomes zero before its extent becomes full.

Suppose now that valuations are realized privately and consider a simple exchange mechanism. Let there be some price $p$ from $(0, \bar{v})$. Both players observe this price. Subsequently, they simultaneously decide whether to say yes or no to trade at this price. These decisions are then publicly announced and trade takes place at $p$ if and only if both parties said yes. We focus on BNE with a positive ex-ante probability of each player saying yes for any given price.

Corollary 2. If $\alpha=0$, the probability that the seller says yes is the same as the probability that the buyer says no. If $\alpha>0$, the former is strictly lower than the latter for any given price $p$.

The logic of the above prediction is strategic. Given mimetic dominance, if the buyer values getting the item more, the seller values keeping it more. The seller is thus reluctant to say yes because conditional on trade, her utility from keeping the object may increase. Hence, in equilibrium the seller needs to be compensated for the loss of mimetic dominance, which leads to a status quo bias.

To further illustrate the above, consider now the elicitation procedure of a multiple price list and, for simplicity, assume that the density of valuations is uniform. Suppose that the full range of prices is given to each party, and they have to indicate whether or not they would be willing to trade at that price. The realization of consumption utilities is again private. An actual price is then drawn randomly and trade is implemented iff both parties said yes at that price as before.

Corollary 3. For any $\alpha>0$, there exists a cutoff equilibrium where the seller's reservation price $p_{s}(v)$ is increasing and the buyer's reservation price $p_{b}(v)$ is decreasing in $v$ with $p_{s}(v)>p_{b}(v)=v$. The gap $p_{s}(v)-p_{b}(v)$ is increasing in $\alpha$.

In the above corollary, the buyer's equilibrium willingness-to-pay (WTP) expresses his basic consumption utility for the item and the seller's willingness-to-accept (WTA) expresses her basic consumption utility and, in addition, her mimetic dominance motive. The above is consistent with the classic finding of an endowment effect which documents a wedge between a seller's WTA and a buyer's WTP (Kahneman, Knetsch, and Thaler, 1990). What drives the endowment effect here, however, is social in that it 
relates to a person's belief about the preferences of others. In turn, the trading mechanism and the presence of private information are key. For example, consider the case of one-sided forced trade whereby for a given price $p$, one of the parties can unilaterally decide whether trade will or will not occur. There, the probability that for any given price the seller wants to force a trade matches the probability with which the buyer does not want to force a trade. This is in contrast with a loss-aversion account, which is about attachment to the object rather than the desires of others, and would therefore still predict a wedge between the seller's WTA and the buyer's WTP. ${ }^{13}$

\subsection{Scarcity}

Mimetic dominance-seeking leads to an increased willingness to keep goods that become relatively more scarce. To illustrate this, consider a setting where $P$ randomly chosen people are assigned a pen and $C$ different randomly chosen people are assigned a mug with $P+C<M$. Each person's consumption utility from obtaining a pen or obtaining a mug is a private i.i.d. draw from a strictly increasing joint cdf $F(p, c)$. Consumption utility exhibits strictly diminishing 'marginal' utility along both the mug and the pen dimension. Suppose that a single randomly picked person $i$ has the right to unilaterally swap her object with a randomly picked other who is assigned the opposite object.

Corollary 4. If $i$ is a mug owner, then the ex-ante probability that she swaps is strictly decreasing in $P$ and strictly increasing in $C$.

The logic of the above prediction is based on the fact that as the scarcity of a good increases, the mimetic dominance motive associated with consuming such a good also increases. All else equal, given diminishing marginal consumption utility, the more scarce the good, the greater the expected boost from mimetic dominance associated with consuming it since the expected maximal unmet desire for the good is greater. An analogous way to express this is to consider consumption only along a single dimension. Given diminishing marginal utility, all else equal, the value of that consumption is higher the lower the consumption of others along this dimension. ${ }^{14}$ A consequence of this is that a person may also care about who she trades with at a given price.

\footnotetext{
${ }^{13}$ For example, Thaler (1980) or Koszegi and Rabin (2006).

${ }^{14}$ For example, the boost in the desire for a Ferrari arises when others desire a Ferrari very much but do not have one. People who only have a single Ferrari may experience an intrinsic taste for a second one, but the difference between the consumption utility of having two versus one of the luxury sports cars is typically much smaller than the consumption utility of one Ferrari. In our setting, a person owning a Ferrari is then unlikely to derive utility from mimetic dominance vis-à-vis others who already have a Ferrari, but may well do so vis-à-vis others who do not have one.
} 


\subsection{Monopoly}

Let us now turn to the implications of mimetic preferences for the classic monopoly problem. The seller can produce a good at a constant marginal cost normalized to zero and derives no consumption utility from the product. Each buyer $i$ has a unit demand for the good associated with a consumption utility of $v_{i}$, an i.i.d. draw from a continuous and strictly increasing cdf $F$ as before. We show that the seller can always achieve a higher revenue by randomly excluding some buyers from the opportunity to buy from the start - provided there are enough buyers left - than by allowing all to buy at the classic optimal monopoly price.

Before demonstrating this, let us first describe some implications in a simple example under the (unrealistic) assumption of consumption utilities being public information. Under standard preferences, the seller wants to sell to each buyer at a price equal to their WTP. In the presence of mimetic dominance seeking, the seller can instead increase her revenue by excluding buyers who want the item most. Consider deterministic and observable selling. ${ }^{15}$

Example 1. Suppose there are three people with $v_{1}=v_{2}=l<h=v_{3}$.

1. If $\alpha<h / 2(h-l)$, the seller's revenue is maximal when selling to each buyer $i$ at $p_{i}=v_{i}$

2. If $\alpha>h / 2(h-l)$, the seller's optimal revenue is given by excluding the high value buyer and selling to the low value buyers at $p=l+\alpha(h-l)$.

While the seller never gains by excluding the lowest valuation type, if the extent of mimetic dominance is sufficiently high, she gains from excluding the high valuation buyer. Such exclusion generates a boost in aggregate demand larger than the highvaluation buyer's maximal willingness to pay. ${ }^{16}$

Consider now the standard monopoly setting. Each buyer's consumption utility is her private information. Given standard preferences $(\alpha=0)$ the seller's classic optimal selling mechanism is to set a single price common to all potential customers and to allow each to buy at will, e.g., Harris and Raviv (1981). Our next result implies that for any $\alpha>0$, if the number of potential buyers is not too small, randomly excluding some buyers from the opportunity to buy the product always permits the seller to achieve a higher revenue.

\footnotetext{
${ }^{15}$ For example if selling was not observable, the seller may have an incentive to tell some buyers that they are the only ones allowed to buy the product, but then sell it to others as well.

${ }^{16}$ The above also illustrates that mimetic preferences lead to different conclusions than a resale motive. While the first point holds in the absence of mimetic dominance regardless of whether or not resale between the buyers is possible, the second point holds only if resale is sufficiently costly. If resale was free, the low valuation buyers would want to sell their objects to the high valuation buyer and anticipating this, their total willingness to pay in equilibrium should be bounded from above by $l+h<2 l+h$.
} 
Proposition 1. For $\alpha=0$, the seller never gains from randomly excluding a buyer and her optimal profit is achieved by posting some price $p^{*}$ to all. For any $\alpha>0$, there exists $M_{\alpha}$ such that if $M>M_{\alpha}$, the seller's revenue is higher when she randomly excludes a strictly positive number of buyers and sets a common price $p^{\prime}$ to the rest.

In contrast to the classic case, in the presence of mimetic preferences, the seller always gains from randomly excluding some potential buyers, as long as there are enough buyers left relative to the classic optimal mechanism of setting the optimal monopoly price for all and allowing each to buy at will. To see the logic, note first that in the standard case, random exclusion simply reduces demand without allowing the seller to extract a higher expected rent from the remaining buyers. Hence, she can only lose from such non-price-based exclusion relative to setting the optimal monopoly price for all. In the presence of mimetic dominance-seeking, however, there is a countervailing psychological effect. The buyers who are still allowed to buy now derive extra utility from consuming the good through mimetic dominance. The unmet excess desire of others generates an increase in their willingness to pay for the product. No matter how small $\alpha$ is, this outweighs the loss from having a smaller consumer base if there are enough consumers left.

Note that the increase in the willingness to pay by the non-excluded consumers is increasing in the number of those excluded since the expected maximal unmet valuation is increasing in the latter. The optimal fraction of potential buyers to be randomly excluded ex-ante may thus be substantial. While more precise claims depend on further details about $F$, as the next example illustrates, the seller may benefit from randomly excluding a substantial fraction of consumers as opposed to just randomly excluding one.

Example 2. Suppose $F$ assigns probability $1 / 3$ to $v_{i}=1$ and $2 / 3$ to $v_{i}=0$. Let $M=18$. The optimal number of buyers to randomly exclude ex ante is 5 for any $\alpha>0.53$ and zero otherwise.

In Section 5 we discuss how the common practices of artificially restricting supply and engaging in scarcity marketing allow firms to extract rents by exploiting this mimetic dominance motive. We also outline how Proposition 1 may capture motives for exclusion based on group affiliations. This generates an incentive for firms to discriminate and for the non-excluded group to oppose anti-discrimination policies.

\section{$3 \quad$ Rivalry in Auctions}

Consider now the implications of mimetic preferences for the classic competitive allocation mechanism of a first-price auction. Potential buyers compete for an indivisible 
object by submitting sealed-bids. The person with the highest bid obtains the good in exchange for her bid. We assume that all potential buyers are serious. As before, each person $i$ 's private consumption utility for this object $v_{i}$ is an independent and private draw from a cdf $F(v)$ over $[0, \bar{v}]$ with a bounded, strictly positive, and continuous density. The seller derives a normalized consumption utility of zero from the object. Given mimetic preferences, each bidder then maximizes her expected utility, which is given by

$$
E\left[v_{i}+\alpha \max _{j \in M}\left\{v_{j}-v_{i}\right\}-b_{i}\right] \text { in case of winning, } 0 \text { otherwise. }
$$

Conditional on winning the auction, a bidder receives her private value and the expected maximal excess taste for the object of those who did not win, net her bid. We denote the number of people randomly excluded from the ability to submit a bid at the start by $K<M-1$, and the number of included active bidders by $N=M-K \geq 2$. As is standard in the literature, we focus on symmetric monotone pure strategy equilibria where the lowest type makes zero expected profit (Milgrom and Weber, 1982).

Proposition 2. The symmetric equilibrium is characterized by a bidding strategy b $\left(v_{i}\right)$ such that

1. If $K=0$, the bidding strategy is independent of $\alpha$.

2. If $K>0$, the bidding strategy and the seller's revenue are increasing in $\alpha$.

3. Holding $K$ constant, the bidding strategy and the seller's revenue are increasing in $M$ for any $\alpha \geq 0$.

4. Holding $N$ constant, the bidding strategy and the seller's revenue are increasing in $M$ iff $\alpha>0$.

First, irrespective of $\alpha$, the seller's expected revenue is increasing in the number of competing bidders. The classic competition result continues to hold: all else equal, greater active competition leads to higher bids and higher revenue. Furthermore, in the absence of exclusion, bidding is independent of the mimetic dominance motive. At the same time, exclusion also leads to an increase in bidding given any positive weight placed on mimetic dominance. This effect increases smoothly as this weight increases. Crucially, holding constant the active number of bidders $N$, as long as mimetic dominance is positive, bids and the seller's revenue are increasing in the number of those excluded.

To see the logic, note that in the absence of exclusion, the auction is efficient in the sense that the winner of the auction is the player with the highest realized valuation. Hence, conditional on winning, there is no utility boost from mimetic dominance and equilibrium bids are independent of $\alpha$. In contrast, in the case of exclusion, the winner 
of the auction may not be the person with the highest valuation for the object. She then derives a utility boost from mimetic dominance since there is a positive chance that those excluded from bidding have an even greater valuation for the object. Holding the number of active bidders constant, this leads to more aggressive bidding by those included. The higher is the number of bidders who are excluded, the greater is the expected maximal unmet valuation, which increases the impact of mimetic dominance.

From this, it follows that under mimetic preferences, both more inclusion (higher $N$ ) and more exclusion (higher $K$ ) — which leads to lower competition — result in higher bids. It is therefore natural to ask whether it is better to have more or less competition from a given pool; that is, whether increasing or decreasing competition leads to greater rents for the seller. The answer depends on the extent of mimetic dominance.

For simplicity, for the two statements below we assume that consumption utilities are drawn uniformly. We denote by $\Pi(M, K)$ the seller's expected revenue when $K$ of the $M$ potential bidders are randomly excluded at the start.

Proposition 3. For any $M$, there exists $\alpha^{*}<\alpha_{M}<1$ such that

1. If $\alpha<\alpha^{*}$, then $\Pi(M, K)$ is decreasing in $K$;

2. If $\alpha>\alpha^{*}$, then $\Pi(M, K)>\Pi(M, 0)$ for any $K \leq K_{M, \alpha}$ where $K_{M, \alpha}$ is increasing in $\alpha$ and $M$;

3. If $\alpha>\alpha_{M}$, then $\Pi(M, K)$ is increasing in $K$;

4. If $\alpha^{*}<\alpha<\alpha_{M}$, then $\Pi(M, K)$ is inverse $U$-shaped in $K$.

If the extent of mimetic dominance is small, the standard result holds and more competition is better such that excluding a potential bidder hurts the seller. For moderate levels of mimetic dominance, the comparative static is non-monotone. Excluding potential bidders, despite the ease in competition, initially raises the seller's expected revenue. The seller's expected revenue under further exclusion continues to exceed that under full inclusion up to a threshold. If the number of excluded crosses this threshold, this process reverses. Furthermore, the comparative static is inverse $U$-shaped in exclusion. The threshold up to which randomly excluding people continues to lead to greater revenue than full inclusion is increasing in the degree of mimetic dominance and in the overall size of the group. Finally, if mimetic dominance is sufficiently high, the seller's expected revenue is strictly increasing in the number of potential bidders excluded.

To see the logic, consider first the standard effect. Exclusion decreases bid amounts because each bidder knows that she faces less competition, and thus she has an incentive to shade more. Furthermore, even holding the bid distribution constant, there 
are now fewer bidders which further decreases the seller's rent. In the presence of mimetic dominance, this standard effect is still fully present. However, there is now a countervailing psychological force. Since the winner may not be the person with the highest private valuation, the winner experiences additional utility from mimetic dominance - the more so the lower her own consumption utility. As the number of excluded bidders increases, competition decreases, but this countervailing psychological force also becomes stronger since the expected maximal unmet excess valuation also increases.

If $\alpha$ is not too small, the seller's revenue initially increases then decreases in the number of randomly excluded bidders. Initially, the force due to mimetic dominance outweighs the standard force due to lesser competition. As long as the mimetic dominance motive is not too high, this balance reverses as the number of excluded individuals reaches a threshold. Past this threshold, further exclusion decreases the seller's revenue.

To further illustrate the economic impact of this psychological motive, it may be useful to point out that random exclusion here may not simply lead to a revenue that is higher than the revenue from full inclusion, but to a revenue that is also higher than the revenue from employing the classic optimal mechanism of running the auction with a carefully-chosen reserve price.

Given independent private values and the standard regularity condition, the seller's optimal revenue is achieved when running the auction with an optimally-set reserve price (Myerson, 1981). The seller allows all bidders to participate, but only sells the item if the winning bid is above a reserve price. The result on the value of competition further implies that under these conditions the revenue from the first-price auction with $M+1$ bidders, maintaining full inclusion and no reserve price, leads to a revenue $\Pi(M+1,0)$ which is greater than the seller's optimal revenue given $M$ bidders (Bulow and Klemperer, 1996). These predictions hold here whenever $\alpha=0$.

If the extent of mimetic dominance-seeking is sufficiently high, however, randomly excluding at least two bidders from a pool of $M$ leads to a higher revenue than from the auction with $M+1$ bidders maintaining full inclusion.

Corollary 5. Suppose that $M \geq 4$. If $\alpha$ is sufficiently high, then for any $K \geq 2$, $\Pi(M, K)>\Pi(M+1,0)$.

Note that the seller's revenue from a first-price auction with any given initial reserve price, maintaining full initial inclusion, is independent of $\alpha$-the winner would still always be the person with the highest consumption utility (as discussed further in what follows). In turn, the above implies that for any feasible $M$, running the auction with any reserve price while maintaining full inclusion generates a lower revenue for 
the seller than the detail-free mechanism of employing sufficient random exclusion at the start and running the auction amongst the included bidders.

Lowest Exclusion. Thus far, exclusion of potential bidders above was random. If instead the $K$ number of bidders who are initially excluded are those who are commonly known to have intrinsic tastes that are lower than the valuations of those included, then the winner of the auction is always the player with the highest valuation. Hence, the winner no longer derives a utility boost from mimetic dominance and this motive will have no bite in equilibrium - just as in the case without exclusion.

We now return to the general setup from the beginning of this Section, but suppose that it is the $K$ lowest valuation bidders who are initially excluded from the opportunity to submit a bid (without disclosing any information about their realized valuations). We refer to this as 'bidding under lowest exclusion' and denote the seller's expected revenue under such lowest exclusion by $\Pi_{L}(M, K)$.

If $\alpha=0$, the average bid under lowest exclusion shall exceed the average bid under random exclusion for any fixed $M$ and $K$. Winning then delivers only one's consumption utility in both cases, but bidders are positively selected under lowest exclusion. In turn, the average bid should be higher under lowest exclusion both because the included bidders come from a positively selected pool - the mechanical effect - and because each active bidder has a lower incentive to shade her bid - the strategic effect of positive selection - leading to a higher bidding strategy amongst those included.

The proposition below also states that for any $\alpha$ and fixed $M$, the seller's expected revenue should be the same under no exclusion and under lowest exclusion (with average bids being higher under lowest exclusion than under no exclusion, due to positive selection). Since in both cases the winner of the auction is the person with the highest consumption utility and since the expectation of the second-highest consumption utility across the active bidders is the same across these cases, the seller's expected revenue in the case of no exclusion equals her expected revenue under lowest exclusion for any fixed $M$.

Proposition 4. Bidding under lowest exclusion is independent of $\alpha$. If $\alpha=0$, then the bidding strategy and the average bid are smaller under random exclusion than under lowest exclusion for any fixed $M$ and $K$. Furthermore, $\Pi_{L}(M, K)=\Pi(M, 0)$ for any $K$ and $\alpha$.

In the empirical investigation presented in the next Section, we rely on the above result. Considering both random exclusion and lowest (non-random) exclusion will help rule out alternative explanations, e.g., whether it is mimetic dominance or scarcity of the opportunity to bid per se which leads to more aggressive bidding. We return to a discussion of this issue after presenting our results. 


\section{Experimental Studies}

We now turn to directly testing the predictions of the model. Our first experiment is in the context of the auction settings outlined in Section 3. Here, people compete for a single good. Our second experiment is the context of a classic exchange mechanism where everyone can potentially attain a good and there is no direct competition between people. These experiments jointly allow us to pin down the proposed mechanism of mimetic dominance and distinguish it from alternative explanations.

\subsection{Auctions}

We begin our investigation in the auction setting for several reasons. First, our theoretical framework makes predictions on the effects of mimetic dominance that run counter to the classic results on competing for a private good. This facilitates a test of mimetic dominance in a setting that is both conceptually interesting and important for applications. Additionally, because the environment always involves the allocation of a single good, a positive effect of exclusion also allows us to rule out a host of alternative explanations related to changes in supply, such as scarcity being a signal of quality, as well as explanations based on consumption externalities, signalling one's income, common forms of social preferences, and scarcity of the opportunity to participate per se.

\subsubsection{Method}

Participants $(N=274)$ were recruited from a university-wide pool to take part in experiments on decision-making. Sessions were conducted with groups of $M \in\{4,6,8\}$, where each participant was assigned to an individual lab station numbered between 1 and 12. Participants earned $\$ 15$ as part of an unrelated study and were then told that they may get the opportunity to participate in an auction. Conditional on having the opportunity, participants could use up to $\$ 15$ of the money they earned from the first study to bid on a good through a first price, sealed-bid auction. The good was a custom T-shirt created specifically for experiments in our lab, which was shown to participants across all sessions. ${ }^{17}$ Participants would write down their bid privately on a sheet of paper. The highest bidder would receive the T-shirt and pay their bid. Everyone else would not receive the T-shirt or pay anything.

Participants took part in one of three treatments. In the Random Exclusion condition, the experimenter announced that she would roll a 12-sided die. If the outcome of

\footnotetext{
${ }^{17}$ We chose to use the custom T-shirt for two reasons. First, because it was created specifically for experiments in our lab, there was no salient anchor value. Second, participants who did not have the opportunity to bid for the shirt could not (easily) obtain it outside of the experiment. The second component was important for our exclusion manipulation.
} 
the die roll matched a lab station number where a participant was sitting, that participant was not given the opportunity to bid for the good. The experimenter would roll the die until $K=\frac{M}{2}-1$ participants were excluded and relinquished their bid sheets, where $M$ was the group size ( $K=\{1,2,3\}$ for $M=\{4,6,8\}$ respectively). The rest of the participants would write down their bids, which were collected by the experimenter. The number of active bidders per session thus corresponded to $N=M-K$.

In the Non-Random Exclusion treatment, participants arriving to the lab were told about the T-shirt as in the other conditions but not about the auction. Each was then asked to indicate the extent to which she would want to own the good on a scale of 1-10. Once these scores were collected, participants learned about the auction and that $K=$

$\frac{M}{2}-1$ people from the group would not have the opportunity to participate. However, unlike in the Random Exclusion treatment, exclusion was based on participant's exante desire for the good: the $K$ individuals who least wanted to own the T-shirt were not given the opportunity to bid for it and this was made common knowledge. The actual 'desire' scores of the participants were never revealed, only that those with the lowest were excluded. The number of active bidders here was thus exactly the same as in the Random Exclusion treatment, $N=M-K$.

We ran two versions of the Baseline treatment $(K=0)$. In both versions, the experimenter announced that everyone in this session would have the opportunity to bid on the shirt, i.e., $K=0$. Participants then wrote down their bids, which were collected by the experimenter. The number of active bidders in this treatment was equal to the group size, $N=M$. The only difference between the two versions of the Baseline treatment was whether participants first indicated the extent to which they would want to own the good, matching the initial procedures of either the Random or Non-Random Exclusion treatments. This allows us to test whether reporting this measure affected bids orthogonally to the treatment variation.

It is important to stress that the nature of exclusion - whether it was random or depended on desire scores - was emphasized and made common knowledge as part of the experiment. Additionally, both the group size $M$ and number of excluded participants $K$ were always emphasized in both written and verbal instructions. Care was also taken to make sure that participants left the lab one at a time and were away from the facility before the next participant departed.

At the end of the experimental session, the highest bidder was paid $\$ 15$ minus her bid and received the shirt. All others were paid $\$ 15$.

\subsubsection{Results}

The average bid size was $\$ 1.41(S E=0.12)$. There were no significant differences in bids between the two versions of the Baseline treatment $(p>.4)$, indicating that 
reporting one's ex-ante taste for the good did not meaningfully affect behavior. We then pool data from the two versions for the analysis that follows. ${ }^{18}$

We first regress the number of active bidders $N$ on bids in the Baseline treatment. The coefficient on $N$ is $\beta=.23, S E=.10$ and is statistically significant $(p=.02)$. This confirms the standard prediction as outlined by Proposition 2 that in the sale of private goods, increased competition leads to more aggressive bidding and higher prices. This provides an appropriate benchmark for examining the effects of exclusion.

Table 1 reports results from an OLS regression with standard errors clustered at the session level. In Column 1, we regress bids on the number excluded $K$ in the Random Exclusion treatment. Here, the exclusion effect is large and significant. Furthermore, the effect of exclusion on average bids is roughly double the impact of adding additional bidders in the Baseline treatment (the competition channel). In Column 3, including dummies for the number of active bidders $N$ only increases the size of the exclusion coefficient. The results are consistent with the logic of Proposition 2.

As outlined in Section 3, the channel of mimetic dominance is muted in the NonRandom Exclusion treatment. When exclusion targets those with the lowest liking scores, in equilibrium the winner still has the highest realized private value in the group. At the same time, the classic effect, holding $N$ constant, now predicts somewhat higher average bids due to positive selection. In turn, this treatment is a conservative test that the impact of Random Exclusion on bids is not due to experimental artifacts such as obtaining a limited opportunity to submit a bid, i.e., the scarcity of opportunity.

Column 2 of Table 1 presents results from the Non-Random Exclusion treatment. The impact of exclusion here is substantially smaller and not significant; controlling for the number of active bidders $N$ in Column 4 shrinks the coefficient to essentially zero. Column 5 compares the relative impact of the two treatments, demonstrating that Random Exclusion has a larger impact on bids than Non-Random Exclusion. These results are summarized in Figures 1 which present the average bids by number of active bidders $N$, comparing the Random Exclusion versus Baseline (Figure 1a) and Non-Random Exclusion versus Baseline treatments (Figure 1b).

Table 2 presents analogous results as Table 1, replacing the number excluded $K$ with a treatment dummy. Columns 1 and 3 correspond to the effects of Random Exclusion, which are large and significant even when controlling for the number of active bidders $N$ (Column 3). On the other hand, as shown in Columns 2 and 4, the effects of Non-Random Exclusion are substantially smaller and not significant in either specification. Together, these results provide support for our hypothesis that exclusion increases average bids, but only when there is a chance that those who are excluded may value the good more than the person who obtains it.

\footnotetext{
${ }^{18}$ Similar results obtain when running the analyses separately for each version of the Baseline treatment.
} 


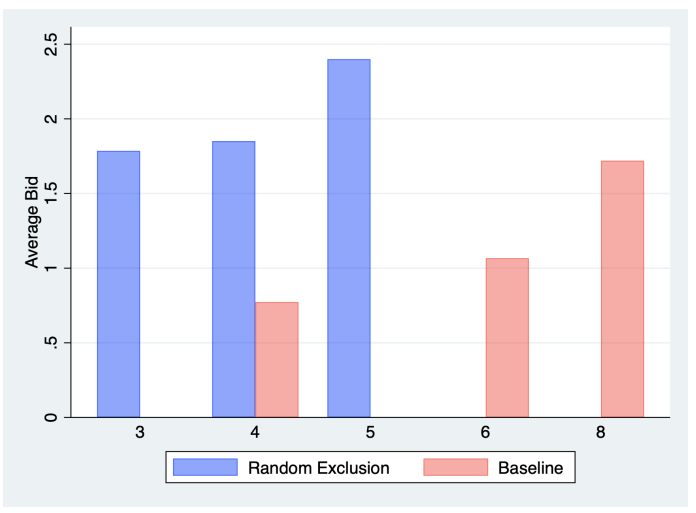

(a) Random vs. Baseline

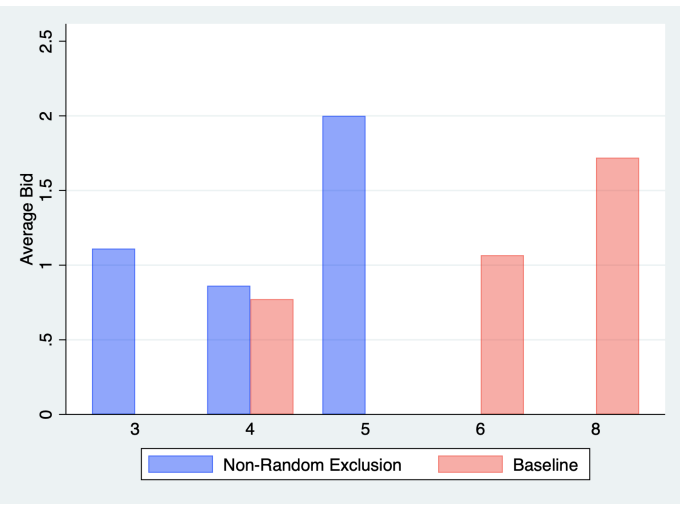

(b) Non-Random vs. Baseline

Figure 1: Average Bids by Number of Active Bidders $N$ Across Treatments

Table 1: Effect of Exclusion $(K)$ on Bids

\begin{tabular}{lccccc}
\hline \hline & $(1)$ & $(2)$ & $(3)$ & $(4)$ & $(5)$ \\
\hline$K$ & $0.42^{* * *}$ & 0.22 & $0.54^{* * *}$ & 0.05 & 0.15 \\
& $(0.11)$ & $(0.15)$ & $(0.19)$ & $(0.09)$ & $(0.14)$ \\
Random & & & & & -0.04 \\
& & & & & $(0.20)$ \\
Random* $K$ & & & & & $0.32^{*}$ \\
Constant & & & & & $(0.16)$ \\
& $1.14^{* * *}$ & $1.18^{* * *}$ & $1.25^{* *}$ & $1.07^{* *}$ & $1.27^{* * *}$ \\
Group Size Dummy & $(0.12)$ & $(0.11)$ & $(0.52)$ & $(0.47)$ & $(0.41)$ \\
$N$ & $\mathrm{~N}$ & $\mathrm{~N}$ & $\mathrm{Y}$ & $\mathrm{Y}$ & $\mathrm{Y}$ \\
\hline
\end{tabular}

${ }^{* * *}: p \leq 0.01,{ }^{* *}: p \leq 0.05,{ }^{*}: p \leq 0.1$. Standard errors clustered at the session level are reported in parentheses below each estimate. Columns 1 and 3 report results comparing Random Exclusion to Baseline; Columns 2 and 4 report results comparing Non-Random Exclusion to Baseline. Columns 3 and 4 include dummies for the number of active bidders $N$. Column 5 compares the relative effects of Random versus Non-Random Exclusion.

Above we focused on average bids between treatments. But we can also use our data to examine expected revenue. To compute expected revenue, we ran a series of Monte Carlo simulations to generate bid distributions using the measured average bid and standard deviations for each group of active bidders $N$ by treatment. We draw $N$ number of bids from these distributions to reproduce the type of data collected in the study, and take the maximum bid from each set of draws. This process is repeated 10,000 for each treatment and group size combination.

Expected revenues by treatment and group size $M$ are presented in Figure 2. We 
Table 2: Effect of Exclusion (binary) on Bids

\begin{tabular}{lcccc}
\hline \hline & $(1)$ & $(2)$ & $(3)$ & $(4)$ \\
\hline Exclusion $(=1)$ & $0.78^{* * *}$ & 0.40 & $1.08^{* * *}$ & 0.09 \\
& $(0.28)$ & $(0.34)$ & $(0.37)$ & $(0.18)$ \\
Constant & $1.12^{* * *}$ & $1.12^{* * *}$ & 0.71 & $1.02^{* *}$ \\
& $(0.11)$ & $(0.11)$ & $(0.61)$ & $(0.50)$ \\
\hline Group Size Dummy & $\mathrm{N}$ & $\mathrm{N}$ & $\mathrm{Y}$ & $\mathrm{Y}$ \\
$N$ & 210 & 206 & 210 & 206 \\
\hline${ }^{* * *}: p \leq 0.01,{ }^{* *}: p \leq 0.05,{ }^{*}: p \leq 0.1$. Standard errors clustered at the session level are reported in \\
parentheses below each estimate. Columns 1 and 3 report results comparing Random Exclusion to \\
Baseline; Columns 2 and 4 report results comparing Non-Random Exclusion to Baseline. Columns \\
3 and 4 include dummies for the number of active bidders $N$.
\end{tabular}

find that the expected revenues from the Random Exclusion versus the Baseline treatment are 4.68 versus 3.84 for $M=8,4.14$ versus 3.03 for $M=6$, and 4.04 versus 1.7 for $M=4$. In line with Proposition 3, both in the Baseline treatment and in the Random Exclusion treatment, the seller's expected revenue is increasing in the number of active bidders. Exclusion increases the seller's expected revenue by more than the competition effect of increasing the number of bidders with full inclusion. Furthermore, in sharp contrast to the standard prediction absent mimetic dominance, the seller's expected revenue is considerably higher under random exclusion than under full inclusion both for each group size $M$ and also when holding the number of active bidders $N$ constant $(M=6$ and $K=2$ versus $M=4$ and $K=0)$.

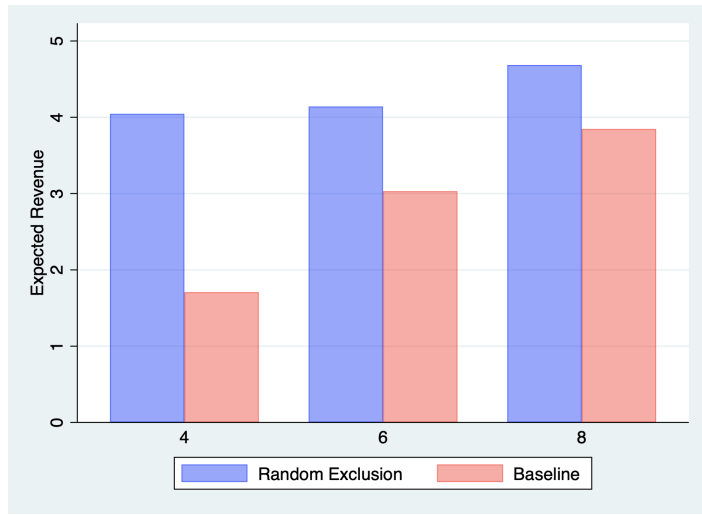

(a) Random versus Baseline

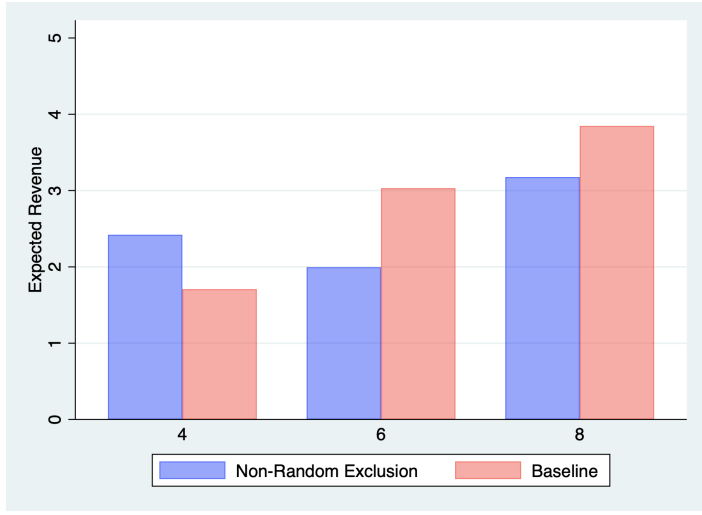

(b) Non-Random versus Baseline

Figure 2: Expected Revenue by Group Size $M$ Across Treatments

In contrast, expected revenues in the Non-Random Exclusion treatment are much closer to those in the Baseline treatment. For any fixed $M$ and $K$, these revenues are 
always below revenues in the Random Exclusion treatment, consistent with $\alpha>0$. In line with Proposition 4, expected revenues in Non-Random Exclusion are roughly similar to those in the Baseline treatment for any fixed $M$ and $K$.

\subsection{Non-competitive Exchange}

The first study provides support for the role of mimetic preferences in a strategic setting where people compete for a single good. These findings are consistent with mimetic dominance, but they may also be consistent with mimetic desire - that is, the idea that a person's utility increases in the excess desires of others irrespective of whether such desires are satisfied or not. Although the item was a standard private good, one may wonder whether the results of the first experiment could have been driven by informational effects due to interdependent values à la Milgrom and Weber (1982) without an exclusionary motive.

Our second study uses the simple setting of non-competitive exchange akin to Proposition 1. Here, mimetic desire, interdependent values without an exclusionary motive more generally, and mimetic dominance-seeking lead to sharply different predictions. Interdependent values and mimetic desire (as opposed to dominance-seeking) would predict no effect of random exclusion. In turn, observing a treatment effect in non-competitive exchange allows us to rule out these alternative explanations.

Consider a setting with $M$ people and $M$ identical goods. Each buyer has a unit demand and consumption utilities are drawn exactly as in Section 3. Consider a simple Becker-DeGroot-Marschak (BDM) selling mechanism. As before, let $K$ denote the number of potential buyers randomly excluded at the start. Subsequently, each nonexcluded individual has to privately submit a non-negative bid. After the bids are submitted, a price is drawn randomly from $[0, \bar{v}]$. according to a positive and bounded density. An item is sold at this common price to each bidder whose bid is weakly higher than this amount and not to others.

Proposition 5. Suppose that each person who submits a bid $b_{i}$ buys at a randomly drawn price $p$ iff $b_{i} \geq p$. In a symmetric equilibrium each player bids $b_{i}=v_{i}+$ $\alpha E \max _{j \in K}\left\{v_{j}-v_{i}, 0\right\}$.

In the absence of exclusion, the bids reveal the buyers' private consumption utilities. In the presence of exclusion, the bids also reflect the influence of mimetic dominanceseeking. Critically, the above difference in bids between the case with and without exclusion depends on the excess desire of others being unmet. If mimetic preferences were purely about excess desire regardless of whether they are met or not, then bids would depend only on $M$ and not on $K$. Similarly, if valuations for the object were simply interdependent in the classic sense, there would be no ex-ante expected difference 
in bids as a function of exclusion. This is true because there is no direct competition between bidders and the distribution of signals about valuations the players receive are the same with and without exclusion for any given $M$. In contrast, mimetic dominanceseeking predicts a clear directional difference.

\subsubsection{Method}

We recruited participants $(N=95)$ from a university-wide pool to take part in a decision-making study. Each participant was randomly assigned to an individual lab station numbered 1-12. As before, participants earned $\$ 15$ as part of an unrelated study and were told that they may have the opportunity to purchase a unique good. The object was the same as in the first study - a custom T-shirt created for the experiment. To measure valuations, we elicited participants' maximum WTP for the good using incentive compatible mechanism described in Proposition 5, which corresponds to the classic Becker-DeGroot-Marschak (BDM) method. Here, after writing down their WTP (bid), the experimenter randomly drew a number between 1 and 15. This number served as the common 'price' $P$. If $P$ was weakly less than a participant's WTP, then she would pay $P$ to the experimenter and receive the object; if $P$ was greater than the participant's WTP, she would not pay anything and not get the object.

Participants were randomized into one of two treatments. In the Baseline treatment, everyone in a session was given the opportunity to privately submit their WTP and potentially purchase the object. In the Random Exclusion treatment, the experimenter rolled a 12-sided die and excluded participants from the opportunity to purchase the good based on their lab station number, using the same method as in our first study. ${ }^{19}$ The non-excluded participants submitted their WTP as in the Baseline condition.

At the end of the experimental session, those whose WTP exceeded $P$ were paid $\$(15-P)$ and received the object. Others were paid $\$ 15$.

\subsubsection{Results}

Figure 3 presents the means (Figure 3a) and distributions (Figure 3b) of participants' WTP for the good by treatment. The distribution of WTP in the Random Exclusion treatment is shifted to the right of the distribution in the Baseline treatment. Consistent with this, the median WTP in the Random Exclusion treatment is $\$ 5$, double the median WTP in the Baseline treatment $(\$ 2.50)$. A two-sample t-test reveals a significant difference between treatment means $(\$ 4.88, S D=4.31$ versus $\$ 3.20, S D=3.28$; $p=.03)$. These results provide direct support for the role of mimetic dominance in valuations: consistent with Proposition 5, people significantly increase their willingness

\footnotetext{
${ }^{19}$ The method of exclusion by group size was the same as in Experiment 1.
} 
to pay for a good if they knew that there are others in their social context whose intrinsic tastes for the object may well be in excess of theirs, but that these tastes were not met.

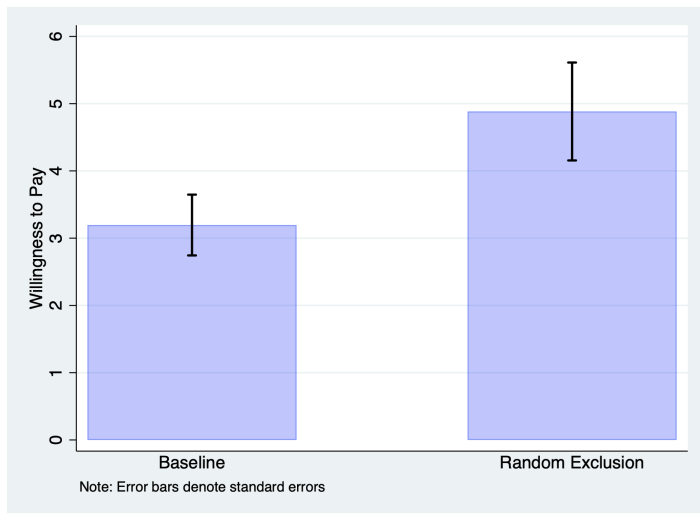

(a)

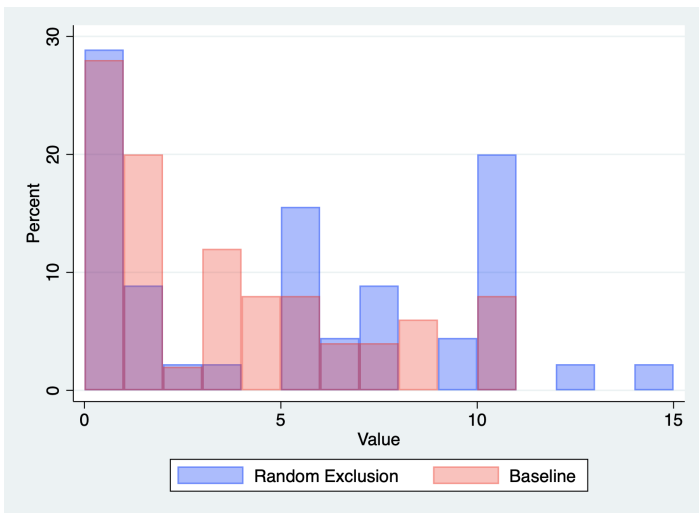

(b)

Figure 3: Willingness to Pay by Treatment

\subsubsection{Estimating Mimetic Dominance}

In this simple setting of basic exchange we can estimate the $\alpha$ parameter of the following equation which captures mimetic preferences as outlined in Section 2.1:

$$
\text { person } i \text { 's valuation }=\overbrace{v_{i}}^{\text {consumption utility }}+\alpha \overbrace{\max _{k \in K}\left\{v_{k}-v_{i}, 0\right\}}^{\text {mimetic dominance }}
$$

We do this in two ways. The first employs standard maximum likelihood estimation to compute a 95\% confidence interval. The second uses Bayesian methods assuming an improper uniform prior of $\alpha \geq 0$.

Both methods yield similar estimates. The mean of the maximum likelihood estimator is 0.94 with a $95 \%$ confidence interval of $(0.86,1.02)$. The mean of the Bayesian estimator is 0.91 with a $95 \%$ confidence interval of $(0.78,1.04)$. In both cases, $\alpha$ is estimated to be significantly greater than 0 , implying substantial weight placed on mimetic dominance in our setting. Interpreting these estimates from a theoretical perspective also allows us to rationalize the strong effect of exclusion in the auction setting on both bids and expected revenues.

\subsection{Discussion}

Our experimental design allows us to rule out a number of alternative explanations as drivers of the observed effect of exclusion. The mechanism of mimetic dominance 
predicts that individuals value an object more when people in their social context have excess unmet desire for it. In order to identify this motive, we need to show that our effect is not driven by people's response to the actual scarcity of the good nor by the scarcity of the opportunity to bid per se. The former may drive up bids if people interpret scarcity as a signal of quality, which could boost demand; the latter may do the same if the opportunity to participate is somehow interpreted in a similar fashion or is valued in of itself.

Our experiments jointly allow us to rule out these alternative explanations. First, there was always a single good being auctioned off across all treatments in Experiment 1 , so object scarcity was held constant. By this token, we can rule out consumption externalities driving our results since these are also constant. Second, the number of people excluded from being able to bid was held constant across the Random and Non-Random Exclusion treatments in Experiment $1 .{ }^{20}$ This allows us to also rule out 'scarcity of opportunity' per se as driving the observed effect. Finally, motives relating to joy of winning or signalling one's income are either held constant across treatments or presumably imply more aggressive bidding in the Baseline than in the Random Exclusion treatment, holding $M$ constant, which predicts the opposite of the observed effect.

Another potential alternative is that our exclusion manipulation introduced opportunities for resale in Experiment 1. We can rule out a resale motive for several reasons. First, whatever external resale opportunity the winner of the auction may have is constant across treatments. An unlikely alternative scenario is that the winner of the object can resell only internally, that is, amongst the randomly excluded bidders. This seems unlikely to occur in practice because bidders were anonymous and care was taken that individuals left the lab one by one. However, even if this unlikely scenario was the case, given independent private values, random exclusion should not increase the seller's revenue - in sharp contrast to what we find empirically. Given the standard regularity condition and players' private information, whatever resale opportunities there may be, as long as $\alpha=0$ it would still need to follow that the seller's revenue satisfied $\Pi(M, K)<\Pi(M+1,0)$ - a prediction which is clearly violated both in our setup and in the data. ${ }^{21}$ Instead, our results are consistent with the prediction of mimetic dominance-seeking, as described in Corollary 5, whereby randomly excluding bidders leads to a greater increase in expected revenue than expanding the number of bidders under full inclusion.

\footnotetext{
${ }^{20}$ In the context of Experiment 2, our model predicts that excluding the lowest valuation participants would result in higher prices than the baseline due to positive selection. In contrast, lowest exclusion in Experiment 1 is not predicted to change expected revenue compared to the baseline treatment (Proposition 4). In turn, it is cleaner to consider the comparison in Experiment 1 than in Experiment 2.

${ }^{21}$ This follows from, for example, Bulow and Klemperer (1996).
} 
As mentioned above, Experiment 1 alone is still consistent with mimetic desire per se or interdependent values without an exclusionary motive. Experiment 2 allows us to rule out these alternative explanations. If people's valuations for the good were driven by such motives - e.g., they like an item more if others like it more as well, irrespective of whether the desires of others are satisfied or not - then there should be no treatment effect in Experiment 2. This is true because the distribution of signals people receive are not affected by random exclusion - these are constant across the treatments - and there is no direct competition. In turn, a person's expectation of the value of obtaining the object, and hence her WTP, would have to be the same with and without exclusion for any given $M$. In contrast, we find that exclusion substantially increases WTP. ${ }^{22}$

\subsection{Related Literature}

A rich literature emphasizes the presence of social motives in people's preferences. A first generation of social preference models focus on consumption externalities, e.g., (Becker, 1974). The next wave of models attempted to explain empirical evidence on costly punishment behavior, such as in the ultimatum game, by considering preferences over relative allocations. Models of inequity aversion (Fehr and Schmidt, 1999) and competitive preferences (Charness and Rabin, 2002) over money assume that people dislike unequal allocations or actively prefer allocations that put them ahead, respectively. A third wave of theory considers whether prosocial or antisocial choices may be a function of imperfect information rather than underlying preferences. Benabou and Tirole $(2006 ; 2011)$ model social behavior in the context of either self or social signaling. Here, the individual treats choices as signals about her type to either others or herself. A related line of work explores the phenomenon of 'moral wiggle room,' where people are found to exploit uncertainty faced by others in order to depart from norms and achieve their preferred selfish allocation (e.g., Dana, Weber, and Kuang, 2007).

In these models, utility is defined over the consumption, money, or the beliefs of others. This is in contrast to our approach which defines utility over others' unmet desires. This distinction is important because it generates novel predictions on the effects of exclusion, which, as we demonstrate both theoretically and empirically, has important implications for markets. For example, in the auction setting, only the winner receives the item and only the winner pays for it while others do not. As

\footnotetext{
${ }^{22}$ Note also that even in the absence of Experiment 2, the results of Experiment 1 are already not consistent with there simply being a common value to the object about which players get i.i.d. signals. In that case, the same average bids and expected revenue should be observed in the Baseline and Random Exclusion treatments given the same number of active bidders. This is not the case in our data. Comparing Random Exclusion with $N=4(M=6$ and $K=2)$ to Baseline with $N=4$ $(M=4$ and $K=0)$, the average bids in the former are substantially greater than those in the latter.
} 
a result, there are no changes in direct consumption externalities regardless of the number of people who can participate. There are also no differences in the monetary payoffs of others across the treatments or in the relevant informational asymmetries, as the allocation mechanism is always common knowledge. Hence, these alternative models will not predict a difference in bids or revenue as a function of exclusion, while mimetic dominance does.

In a line of work closer to our own, Frank (1985) models 'keeping up with the Jonses' effects through a demand for positional, or status, goods. The existence of such goods is taken as a primitive. In the model, people not only care about their personal consumption utility from positional goods, but also the hierarchy of observable consumption amongst others. In particular, people's utility from a positional good is a function of the percentile ranking of their own consumption of the good relative to the overall population's consumption of it. If people make choices non-cooperatively, the resulting preference to consume more than others leads to the overconsumption of this positional good compared to non-positional goods with similar features. ${ }^{23}$

Our framework is conceptually distinct from this literature: in contrast to such a direct consumption externality, the mimetic dominance motive is defined over the unmet desires of others for what one has rather than over the consumption space independent of those desires. Importantly, the mimetic mechanism makes distinct empirical predictions. As noted above, consumption externalities such as Frank (1985) would predict no effect of exclusion in our experiments. At the same time, positional externalities are consistent with the implications of mimetic dominance-seeking, which implies an incentive to surpass the consumption of others, in quality or kind, if this allows a person to increase the unmet desires of others for what she has. The framework of mimetic dominance-seeking may thus be viewed as a psychological foundation for the demand for positional goods, as well as a quest for status more generally, while making a host of additional predictions for individual decision-making and market behavior. We expand on this further below.

\section{Broader Implications}

Mimetic dominance-seeking implies a utility benefit from exclusion: a person enjoys a good more if there are others in her social context who desire this good in excess of her, but do not have it. This Section explores some implications of the mimetic dominance motive for phenomena in markets and in the domain of political economy.

\footnotetext{
${ }^{23}$ See also Heffetz and Frank (2011) for a review of the literature on status-seeking, with status goods as a special case.
} 
Artificial Scarcity and Exclusion. As captured by Proposition 1, our framework predicts that firms and marketers can extract greater rents by artificially limiting the actual (or perceived) supply of goods and services. Examples of such practices abound. Established restaurants and nightclubs make people queue in lieu of expanding capacity despite ample opportunities to do so or raising the price. Nightclubs grant random access to some but not others despite there being enough room for all. ${ }^{24}$ Firms regularly introduce new consumer products at artificially low quantities, e.g. a new phone model, despite overwhelming demand. As discussed in Becker (1991), these phenomena are puzzling from the perspective of standard economics since a firm should either raise the price and/or expand capacity; firms should not choose to restrict supply while profit opportunities are positive. His paper highlights the widespread prevalence of artificial scarcity but ultimately cannot explain it in a parsimonious manner. In contrast, our model rationalizes the use of artificial scarcity as a way to increase profits. Firms prefer random exclusion to setting the optimal monopoly price to all because people who end up obtaining the good or service will derive utility from mimetic dominance, knowing that others may have excess desire for the good that is ultimately unmet. The increase in their willingness to pay more than compensates for shrinking the pool of potential consumers.

Indeed marketers often employ a variety of seemingly arbitrary methods of exclusion to create the perception of scarcity. Creating such a perception is one of the six 'Weapons of Influence' highlighted in Cialdini's bestselling book on persuasion and marketing titled Influence: Science and Practice (1984). Techniques include limited time offers, highlighting that there are 'only' a few goods left (common in online marketplaces), or only allowing people with last names beginning with certain letters of the alphabet to purchase a good (a classic infomercial practice). As Cialdini emphasizes, these methods are effective because they make salient the joy of possessing a good that others are excluded from. ${ }^{25}$ Other practitioner guides explain the effectiveness of scarcity techniques in a similar fashion, stating that they increase demand by making the eventual owners 'feel powerful' over those with unmet desires for the same products. $^{26}$

\footnotetext{
${ }^{24}$ A noteworthy example was the nightclub Studio 54 in Midtown Manhattan, described by Andy Warhol as "dictatorship on the door but a democracy on the dance floor." Here, "guestlist and celebrities were allowed in a separate entrance through the back door but the general public lined the streets in the hope to be given the chance to pay to enter the club. 'When Steve was running the club he would be very difficult with people on the front door,' says Mark Fleischman, previous Studio 54 owner and author of the recently released Inside Studio 54 book. 'He'd say, "you can't come in, I don't like your shirt, get out." People would wait for hours and not be let in." See, https://www.loudandquiet.com/interview/studio-54-the-story-of-the-most-famous-club-inthe-world-remembered-by-the-man-who-just-had-to-buy-it/

25 "The joy is not in experiencing a scarce commodity but in possessing it" (p. 267, emphasis his).

${ }^{26}$ For example, SUMO's guide to scarcity marketing states that "Scarce items make people feel powerful: Snagging a scarce item means you have access to something other people want but can't have-which
} 
The use of such scarcity marketing techniques whereby the perceived access to a good or service is randomly limited may seem perplexing because, if anything, potential consumers may be discouraged by the prospect of attempting to obtain an item that ends up being sold out. In contrast, our framework predicts that scarcity marketing increases demand because it exploits the mimetic dominance motive: people are led to believe that there are others who may want the goods more but cannot have them, which increases their willingness to pay as a result.

Price-based Exclusion and Veblen Goods. Economist have long considered the prevalence of status goods and so-called 'Veblen effects,' whereby the demand for certain goods increases as its price increases. The goods that display this seeming violation of the law of demand are often characterized by their exclusivity and luxury (excess). A line of work relates 'Veblen effects' to the propensity to signal one's income status for downstream non-pecuniary benefits. For example, Bagwell and Bernheim (1996) consider a setting where people allocate their income across two types of goods: observable 'conspicuous' goods, such as a sport car, and less observable non-conspicuous, goods, such as private home decor or art displayed at home. ${ }^{27}$ It is assumed that there are non-peculiar benefits from signalling high income to social contacts. In this framework, a 'Veblen effect' is said to arise when rich people consume a higher-priced but otherwise equivalent version of the 'conspicuous' good. However, the conditions which generate such effects also generate perhaps counter-intuitive predictions. For example, a more efficient method of signaling income would be for richer people to destroy resources publicly, or simply just post their incomes. The framework also suggests that firms have an incentive to produce perfect substitutes that only differ in price, creating a 'budget' product and a 'luxury' product of the same quality.

Mimetic dominance-seeking provides an alternative and perhaps complementary channel to signalling. In our framework, in the presence of heterogeneous income, people's demand for a luxury good may increase with its price irrespective of observability with regards to one's income status or consumption. 'Veblen effects' arise through heterogeneity in income and tastes, such that a high price creates exclusion. Specifically, increasing prices leads consumers who may very much desire the good to no longer be able to attain it, which generates mimetic dominance utility amongst those who may like the good less but can still afford it. Through this channel, raising the price of the good may increase total demand. A simple stylized example provides intuition.

Example 3. Suppose there are $M$ consumers and each consumer is rich with probability $\gamma$ and poor with probability $1-\gamma$. A monopolist produces a good at zero marginal cost. Each person has a unit demand for the good and her consumption utility is an i.i.d.

gives the owner power" (https://sumo.com/stories/scarcity-marketing).

${ }^{27}$ See also Pesendorfer (1995). 
draw from a strictly increasing $F(v)$ over $[0, \bar{v}]$. The only ex-ante difference between rich and poor is that poor consumers face a tighter budget constraint. For simplicity, suppose that the poor cannot spend more on the good than some number $Z<\bar{v}$.

If the price of the good is less than $Z$, total expected demand is $M[1-F(p)]$. Such demand reflects the basic willingness to pay for the product. In contrast, if the price is greater than $Z$, there is no demand by poor consumers, but the expected demand is now $\gamma M[1-F(p-\alpha g(p))]$ for some function $g(p)$, where $0<g(p)$ as long as $p<\bar{v}$. - rich consumers with an intrinsic taste well below $p$ will now also want to buy the product. It is easy to see that, depending on $F$ and $\gamma$, demand may indeed be higher than when the price is below $Z$, emblematic of the standard 'Veblen effect. ${ }^{28}$

In the above stylized example, it may also follow that even if a firm could engage in third-degree price discrimination and sell to the rich and poor at different prices, it prefers not to do so even if such a sale could be certified and it was clear at which price a particular good was bought. Instead, the firm may prefer to shut down the market for poorer individuals. It would not produce a perfect low-priced 'budget' substitute: the prospect of low-income individuals having access to the same good would diminish the impact of mimetic dominance and crowd out demand from the rich. This rationalizes why luxury firms rarely advertise budget products under the same umbrella; when a firm does offer both low and high priced goods, the former is typically advertised under a different brand and stresses accessibility while the latter stresses quality (e.g., Giorgio Armani versus Armani Exchange).

Our model also makes predictions on the types of objects that that are more likely to display 'Veblen effects' due to mimetic dominance. Since the effects arise as a function of unmet desire, quality, for which there are no close cheap substitutes, plays an important role in determining which types of goods are more likely to generate 'Veblen effects' (a Ferrari is more likely to be a Veblen good than a Toyota Tercel). A higher quality good is associated with a greater intrinsic taste for it and will be linked to higher levels of mimetic dominance when this desire is unmet. Thus, pricebased exclusion will generate a larger shift in the demand amongst those who can consume it. This is also in contrast to pure signaling motives where perceptions of quality do not factor into 'Veblen effects' per se. Additionally, our framework allows for such exclusive goods to be enjoyed in private as well, such as intimate dinners at an expensive restaurant, art collections housed in a private gallery, or luxury amenities of a gated community, since perceptions of exclusion rather than observability of one's own consumption is the key driver for increased demand in our framework. ${ }^{29}$

\footnotetext{
${ }^{28}$ The logic extends to the case where there is a more general distribution of budget constraints across the potential consumers. Then the induced demand may well be smoothly upward sloping in price over a large range of prices.

${ }^{29}$ Note that in our basic setup we assumed for simplicity that utility was quasi-linear in money. While
} 
Importantly, we do not claim that the observability of consumption is not an important factor in the demand for luxury goods. Work by, for example, Heffetz (2011) and Bursztyn, et al. (2018) has shown that visibility plays a significant role in the consumption of some premium goods. In fact, visibility may amplify mimetic dominance motives by ramping up desire in those who cannot afford the good or by shaping the social context. We also do not aim to minimize signaling as a potential motive. Rather, we argue that mimetic preferences provide a distinct and potentially complimentary channel which further increases the predictive power for which goods are more or less likely to generate 'Veblen effects.'

Redistribution versus Exclusion. Redistributive policies such as progressive taxation are common tools for mitigating income inequality. However, political scientists and economists are often puzzled by opposition to these policies by the U.S. electorate, particularly amongst the poor and lower middle-class. ${ }^{30}$ Prior work has argued that such opposition may stem from the 'prospect of upward mobility' (e.g., Benabou and Ok, 2001), whereby people would prefer to avoid higher taxes given their prospects of moving up higher on the income ladder. Other work argues for the role of motivated beliefs about the potential of upward mobility, which function to counteract limited willpower (Benabou and Tirole, 2006). In the presence of income heterogeneity, mimetic dominance-seeking offers a potential complimentary and distinct motive for the opposition to some redistributive policies, particularly amongst the poor-butnot-poorest individuals. Even if such policies provide greater social insurance, they may decrease the mimetic dominance utility associated with the respective group's consumption.

Consider for example the question of increasing the minimum wage. An increase in the minimum wage has positive implications for those currently earning the minimum wage. By having more money, they can purchase goods that previously only those who are richer could afford. Our framework predicts why opposition to such a policy may be especially strong amongst those who earn just one bracket above the current minimum wage. Similar to the Veblen logic described above, this group is deriving a utility boost from consuming products that the lower income group - who earn the current minimum wage - cannot afford. Their utility boost associated with mimetic dominance comes vis-à-vis those with tighter budget constraints. Increasing the minimum wage would eliminate this boost, which leads the poor-but-not-poorest earning group to oppose the policy. In fact, the negative effect of a higher minimum wage on mimetic dominance motives may well be the largest for this poor-but-not-poorest group. Given

we believe that this is a useful assumption in the context of smaller purchases, here one can relax this assumption for the pooerer group.

${ }^{30}$ See e.g., Kenworthy and McCall (2008). 
heterogeneity in tastes, others closer to the top of the income distribution will still continue to enjoy various goods that those below them crave more, but cannot afford. Specifically, even holding the social context constant, the mimetic dominance boost derived by those closer to the top of the distribution is more likely to come vis-à-vis people who are not at the bottom of the income ladder - and their consumption will not be directly affected by redistributive policies targeting the bottom of the distribution.

This prediction is consistent with the findings of Kuziemko et al. (2014), who present survey evidence that people just one income notch above the minimum wage threshold oppose a minimum wage increase the most even after controlling for demographics. In our framework, a policy which sustains exclusion and inequality may be more popular than a redistributive policy because the gain in terms of social insurance will be outweighed by the loss of mimetic dominance.

Immigration and Economic Nationalism. The mechanism described in the paper is also broadly consistent with the phenomenon whereby 'natives' may want to limit the rights of 'immigrants,' even if such exclusion comes at a material cost to the former. By restricting access to certain rights and institutions that some immigrants desire more, natives can derive extra utility from them through mimetic dominance. This also helps explain the familiar notion of 'pulling up the ladder,' whereby people who have recently immigrated oppose further immigration. ${ }^{31}$ Even if further immigration were to increase their own material well-being and productive social networks, recent immigrants who know others who would like to immigrate as well-thereby gaining access to opportunities and institutions available in the host country - may oppose additional immigration because this would lead to a drop in their own mimetic dominance (which is derived from access to this set of benefits).

Politicians appear aware of these concerns, describing access to national institutions through the perspective and desires of those outside of the nation. Often this rhetoric takes the form of highlighting outsider desire, such as in the United Kingdom where the National Health Service is often referred to as the 'envy of the world,' or in the United States, where economic success is celebrated as the US economy 'once again, being the envy of the entire world. 32

Although our analysis has focused on the individual's mimetic dominance vis-à-vis

\footnotetext{
${ }^{31}$ For example, a recent Pew Research survey showed that half of all foreign-born whites stated that new immigrants threaten US values rather than strengthen them. A quote from a recent immigrant, who came in 2003, sums up this sentiment "I think that enough immigrants entered this country" (https://archive.sltrib.com/article.php?id=4132971itype=CMSID).

${ }^{32}$ e.g., https://www.telegraph.co.uk/news/2019/06/19/donald-trump-2020-us-president-launches-reelection-campaign/. President-elect Biden referred to democratic elections in similar terms: "But that patience has been rewarded now for more than 240 years, the system of governance has been the envy of the world." https://www.independent.co.uk/news/world/americas/us-election-2020/bidenwin-votes-count-2020-election-trump-b1626691.html
} 
her social context, such preferences can also apply to the joy of identifying with a group and the rivalry between groups. In particular, people may enjoy identifying with a group they can belong to and derive pleasures from the goods and attributes this group as a whole possesses. The value of in-group identification is then amplified if that group possesses attributes or consumes goods that members of another group would like more, but do not have. Indeed, given the mimetic mechanism, it is the exclusion of out-of-group members from such goods or attributes which causes a form of pride and generates a utility boost from one's group identity. To protect the value of such group identities, maintaining exclusion is important, which generates psychological barriers to inter-group trade.

Discrimination and Social Exclusion. Finally, mimetic-dominance seeking may also help rationalize aspects of social exclusion and what appears to be 'taste-based' discrimination. In a framework termed stratification economics, members of social groups compete over relative positions in exogenous social hierarchies (Darity et al., 2017; Darity et al., 2015). Higher positions provide members with a number of privileges including exclusive access to a broad category of club goods. In this framework discrimination is a 'rational' response by dominant groups to maintain access to these privileges, serving as a tool for exclusion so that their own supply is protected.

Our model provides a distinct and complimentary account through the psychological motive of mimetic dominance-seeking. The framework predicts exclusionary and discriminatory policies even in the absence of an exogenous hierarchies or the associated club goods being rivalrous on the relevant margin. Specifically, majority groups may employ discriminatory policies in order to boost their own utility from consuming private goods. That is, the unmet desires of the excluded or persecuted minority yield additional utility benefits associated with consumption of those goods, which increases incentives for discrimination. ${ }^{33}$ Exclusion based on salient (or easily observable) characteristics such as race or ethnicity facilitates mimetic dominance-seeking by members of the majority group. The logic of how this motive generates incentives for discrimination is similar to the other cases in the preceding discussion.

\section{Conclusion}

Our paper proposes that an individual's valuation from consuming an item or possessing an attribute is boosted by a comparative term reflecting others' unmet desire for it. This implies a form of dominance seeking through desire and leads to a preference

\footnotetext{
${ }^{33}$ For example, see real estate ad for properties in La Jolla, CA, a community marked by a 'gentleman's agreement' not to sell housing to Jews: "The very fact that you live in La Jolla puts you in a special class"(Stratthaus, 1996). Private golf clubs have a long history of race-based discrimination (Sawyer, 1993).
} 
for exclusion. Our model of mimetic dominance-seeking helps explain a host of market anomalies and generates novel predictions for competition and political economy. We present experimental evidence consistent with the predictions of mimetic preferences across several exchange environments. Randomly excluding people from the opportunity to bid in first-price auctions for a private consumption good increases average bids and revenue. The seller's rent is greater under random exclusion than when competition is increased by allowing for more bidders. Mimetic dominance also generate significant frictions in basic trade: a person's demand for a good increases substantially when others are explicitly excluded from the opportunity to buy the same kind of good. Our model naturally generates 'Veblen effects' and rationalizes the use of artificial restrictions to supply by firms. The framework also provides a novel motive for attitudes against redistribution and immigration, as well as points to a distinct psychological mechanism for inter-group favoritism and discrimination.

Future work can greatly refine and expand the predictions described in our paper. From a theoretical perspective, mimetic preferences may have important implications to a variety of pricing and mechanism design problems where people enjoy consumption through exclusion in the fashion described. Mimetic dominance may potentially help explain mispricing in financial settings, such as the well-known puzzle of IPO underpricing (Ritter and Welch, 2002). There, initial supply is consistently dwarfed by demand, which leads to anomalously large first-day returns. We believe that this may partially be due to underwriter firms responding strategically to mimetic dominance motives amongst potential investors.

Followup research can also explore how the provision of property rights and the corresponding features of excludability interact with the mimetic dominance motive, or how social institutions such as systems of honour may both amplify and channel mimetic dominance-seeking. Additionally, we believe that the mimetic mechanism may have implications for the quest for superiority in the domain of moral esteem. This could potentially drive the more intense pursuit of certain moral attributes while at the same time also creating an incentive for making these attributes artificially scarce. Mimetic dominance generates a motive for stratification across moral dimensions, where people seek moral credentials for themselves while denying the capacity for the same broadly-desired credentials in others.

Our model has a number of significant limitations and may generate counterintuitive predictions in some settings. We link mimetic dominance directly to people's consumption utility, but we consider a specific form thereof. Future work may consider more general models of the motive we propose and explore more general implications thereof. An important ingredient of our model is one's social context. We do not endogenize this comparison set, which may be affected by attention, memory and salience. 
Additionally, in many contexts a preference for exclusion may be veiled or enhanced by factors outside of our model, such as the desire to conform to norms and forms of behavior that would, for example, prevent people for explicitly paying for social exclusion. Furthermore, focus on some domains may diminish the mimetic motive in another domains. Future research could also explore psychological factors that determine how mimetic dominance-seeking interacts with broader economic conditions such as negative or positive shocks.

\section{References}

[1] St. Augustine of Hippo. 2009. The City of God. Ed. and Trans. Marcus Dods. Hendrickson Publishers, Peabody, MA.

[2] Bagwell, Laurie S. and B. Douglas Bernheim. 1996. Veblen Effects in a Theory of Conspicuous Consumption. American Economic Review, 86(1): 349-373.

[3] Banerjee, Abhijit. 1990. Envy. in Economic Theory and Policy: Essays in Honour of Dipak Banerjee. Edited by Bhaskar Dutta, Shubhashis Gangopadhyay, Dilip Mookherjee, and Debraj Ray. Oxford University Press.

[4] Becker, Gary. 1974. A Theory of Social Interactions. Journal of Political Economy, 82(6): 1063-93.

[5] Becker, Gary. 1991. A Note on Restaurant Pricing and Other Examples of Social Influence on Prices. Journal of Political Economy, 99(5): 1109-16.

[6] Benabou, Roland and Efe Ok. 2001. Social Mobility and the Demand for Redistribution: The Poum Hypothesis. Quarterly Journal of Economics, 116(2): 447-487.

[7] Benabou, Roland and Jean Tirole. 2006. Incentives and Prosocial Behavior. American Economic Review, 96(5):1652-1678.

[8] Benabou, Roland and Jean Tirole. 2006. Belief in a Just World and Redistributive Politics. Quarterly Journal of Economics, 121(2): 699-746.

[9] Bordalo, Pedro, Gennaioli, Nicola, and Andrei Shleifer. 2013. Salience and Consumer Choice. Journal of Political Economy, 121(5):803-843.

[10] Bulow, Jeremy and Paul Klemperer. 1996. Auctions versus Negotiations. American Economic Review, 86(1): 180-194.

[11] Bursztyn, Leonardo, Bruno Ferman, Stefano Fiorin, Martin Kanz, and Gautam Rao. 2018. Status Goods: Experimental Evidence from Platinum Credit Cards. Quarterly Journal of Economics, 133(3):1561-1595. 
[12] Charness, Gary and Matthew Rabin. 2002. Understanding Social Preferences with simple tests. Quarterly Journal of Economics, 117:817-869.

[13] Cialdini, Robert B. Influence: The Psychology of Persuasion. Vol. 55. New York: Collins, 2007.

[14] Dana, Jason, Weber, Roberto, and J. Xi Kuang. 2007. Exploiting Moral Wiggle Room: Experiments Demonstrating an Illusory Preference for Fairness. Economic Theory, 33:67-80.

[15] Darity, William, Hamilton, Darrick, and James B. Stewart. 2015. A Tour de Force in Understanding Intergroup Inequality: An Introduction to Stratification Economic. Review of Black Political Economy, 42: 1-6.

[16] Darity, William, Hamilton, Darrick, Mason, Patrick L., Price, Gregory N., Davila, Alberto, Mora, Marie T., and Sue K. Stockly. 2017. Statification Economics: A General Theory of Intergroup Inequality. The Hidden Rules of Race: Barriers to an Inclusive Economy, 35 - 51.

[17] Frank, Robert. 1985. The Demand for Unobservable and Other Nonpositional Goods. American Economic Review, 75(1): 101-16.

[18] Fehr, Ernst and Klaus Schmidt. 1999. A Theory of Fairness, Competition, and Cooperation. Quarterly Journal of Economics, 114: 817-868.

[19] Frankel, David (director). The Devil Wears Prada. 20th Century Fox Pictures, 2006

[20] Girard, Rene. 1966. Deceit, Desire and the Novel: Self and Other in Literary Structure. Baltimore: Johns Hopkins University Press.

[21] Girard, Rene. 2002. Oedipus Unbound: Selected Writings on Rivalry and Desire. Ed. by Mark R. Anspach. Stanford: Stanford University Press.

[22] Harris, Milton and Arthur Raviv. 1981. A Theory of Monopoly Pricing Schemes with Demand Uncertainty. American Economic Review, 71: 347-365.

[23] Heffetz, Ori. 2011. A Test of Conspicuous Consumption: Visibility and Income Elasticities. Review of Economics and Statistics, 93(4): 1101-1117.

[24] Hirschman, Albert. 1979. The Passions and the Interests: Political Arguments for Capitalism Before Its Triumph. Princeton University Press.

[25] Hont, Istvan. 2015. Politics in Commercial Society. Adam Smith and Jean-Jacques Rousseau. Harvard University Press. 
[26] Hobbes, Thomas. 1998. Man and Citizen. Originally published, 1642 and 1658. Hackett Publishing, Cambridge, MA.

[27] Kagel, John and Dan Levin. 2014. Auctions: A Survey of Experimental Research. In: J. Kagel and A. Roth, Eds. Handbook of Experimental Economics, Vol. 2. Princeton University Press.

[28] Kahneman, Daniel, Knetsch, Jack, and Richard Thaler. 1990. Experimental Tests of the Endowment Effect and the Coase Theorem. Journal of Political Economy, 98: $1325-1348$.

[29] Kenworthy, Lane and Leslie McCall. 2008. Inequality, Public Opinion and Redistribution. Socio-Economic Review, 6: 35-68.

[30] Koszegi, Botond and Matthew Rabin. 2006. A Model of Reference-Dependent Preferences, Quarterly Journal of Economics, 121(4): 1133-1165.

[31] Koszegi, Botond and Adam Szeidl. 2013. A Model of Focusing and Economic Choice, Quarterly Journal of Economics, 128(1): 53-104.

[32] Kuziemko, Ilyana, Buell, Ryan, Reich, Taly, and Michael Norton. 2014, "LastPlace Aversion": Evidence and Redistributive Implications. Quarterly Journal of Economics, 129(1): 105-149,

[33] Lewis, C. S. The Inner Ring. Memorial Lecture at King's College, University of London. P. Zimbardo, The Lucifer effect (1944): 258-259.

[34] Milgrom, Paul and Robert Weber. 1982. A Theory of Auctions and Competitive Bidding. Econometrica 50: 1089-1122.

[35] Myerson, Roger. 1981. Optimal Auction Design. Mathematics of Operation Research, 6(1): 58-73.

[36] Pesendorfer, Wolfgang. 1995. "Design innovation and fashion cycles." American Economic Review: 771-792.

[37] Rousseau, Jean-Jacques. 1755. A Discourse on the Origins and Foundations of Inequality. Trans. Helena Rosenblatt New York Bedford, St Martins, 2011.

[38] Rousseau, Jean-Jacques. 1762. Emil or on Education. Trans. Allan Bloom. New York: Basic Books, 1979.

[39] Ritter, Jay R., and Ivo Welch. 2002. A Review of IPO Activity, Pricing, and Allocations. The Journal of Finance 57: 1795-1828. 
[40] Sawyer, Thomas H. 1993. Private Golf Clubs: Freedom of Expression and the Right to Privacy. Marquette Sports Law Review, 3.

[41] Stratthaus, Marry Ellen. 1996. Flaw in the Jewel: Housing Discrimination against Jews in La Jolla, California. American Jewish History, 84: 189-219.

[42] Thaler, Richard. 1980. Towards a Positive Theory of Consumer Choice. Journal of Economic Behavior Organization, 39-60.

[43] Varian, Hal. 1976. Two problems in the theory of fairness, Journal of Public Economics, 5(3-4): 249-260.

[44] Veblen, Thorstein. 1899. The Theory of the Leisure Class. Reprint 1965, MacMillan: New York. 


\section{Appendix A: Proofs}

Proof of Corollary 1. Suppose person $i$, who has the object. If $v_{i}<v_{j}$, an event which occurs with ex ante probability $1 / 2$, trade takes place iff $(1-\alpha) v_{i}+\alpha v_{j}-\varepsilon<v_{j}-\varepsilon$. The probability that this inequality is satisfied is decreasing in $\alpha$ and becomes zero for any $\alpha$ sufficiently high. If $v_{i}>v_{j}$, trade never occurs for any $\alpha \leq 1$.

Proof of Corollary 2. Consider $p \in(0, \bar{v})$. If $\alpha=0$, the seller accepts iff $p \geq v_{s}$ and the buyer accepts iff $p \leq v_{b}$. Consider $\alpha>0$. If the seller says no, the buyer's payoff is independent of whether she says yes or no. The buyer's strategy must be monotone in equilibrium since, holding the seller's strategy constant, the buyer's utility from the object is increasing in $v_{b}$ for any $\alpha<1$. If the buyer says 'no,' this affects the seller's utility, but whether the seller says 'yes' or 'no,' has no bearing on the seller's payoff. Since the buyer's strategy is given by a cutoff, the seller's value of keeping the object must be increasing in $v_{s}$ for any $\alpha<1$.

Let $\underline{v}_{b}$ be the inf buyer type saying yes, let $\bar{v}_{s}$ be the sup seller type saying yes. Suppose that $\underline{v}_{b}<\bar{v}_{s}$. Then $\bar{v}_{s}<p$ for any $\alpha>0$. It follows that $\underline{v}_{b}<p$. This is, however impossible. Conditional on trade the buyer's expected utility would then be $\underline{v}_{b}+\alpha z-p$, where $z$ is bounded by $\bar{v}_{s}-\underline{v}_{b}$. Hence, $\underline{v}_{b}+\alpha z-p<(1-\alpha) \underline{v}_{b}+\alpha \bar{v}_{s}-p<$ $(1-\alpha)\left(\underline{v}_{b}-p\right)<0$. Suppose that $\underline{v}_{b}=\bar{v}_{s}$. Then, the seller has an incentive to deviate as long as $\alpha>0$. Hence, $\underline{v}_{b}>\bar{v}_{s}$ must hold.

Proof of Corollary 3. Consider the case where the buyer's reservation price is $p_{b}\left(v_{b}\right)=$ $v_{b}$ and the seller's reservation price $p_{s}\left(v_{s}\right)$ solves $(1-\alpha) v_{s}+\alpha E\left[v \mid v>p_{s}\right]=p_{s}$. To show that this is an equilibrium note that since conditional on trade $v_{b}>v_{s}$, and the buyer does not experience mimetic dominance. To check for the seller, note that differentiating $(1-\alpha) v_{s}+\alpha E\left[v \mid v>p_{s}\right]=p_{s}$ with respect to $p_{s}$, the RHS has a derivative of 1 and the LHS has a derivative of $\alpha / 2$. Hence, there is a unique solution and this solution is strictly increasing in $v_{s}$ and $\alpha$.

Proof of Corollary 4. Take any realization $\left\{v_{i, p}, v_{i, c}\right\}$. With a slight abuse of notation, let $v_{i, p}^{+}$denote the consumption utility of an additional pen to a player $i$ and $v_{i, c}^{+}$denote the consumption utility of an additional mug to player $i$ relative to a given allocation. Given concave consumption utility, person $i$ prefers the allocation where she gets a pen to the the allocation where she gets a mug iff $v_{i, p}+\alpha E \max _{j \in M}\left\{v_{j, p}^{+}-v_{i, p}, 0\right\} \geq$ $v_{i, c}+\alpha E \max _{j \in M}\left\{v_{j, c}^{+}-v_{i, c}, 0\right\}$. By strict concavity of the consumption utility, an increase in $P$ leads to a decrease in $v_{j, p}^{+}$, for any $j$, and, given random allocation of the additional pens, with positive probability, to a strict decrease, hence, a strict decrease 
in the LHS of the inequality. Similarly, an increase in $C$ leads to a decrease in $v_{j, c}^{+}$and, with positive probability, to a strict decrease, hence a strict decrease in the RHS of the inequality.

Proof of Proposition 1. Let the seller-optimal price be $p_{M}$ and the associated expected profit, per buyer, be $V$. If $\alpha=0$, the seller's profit is maximal by charging some $p_{M}$ to all buyers with an expected overall profit of $M V$. Consider $\alpha>0$. Excluding a single buyer leads to an expected loss of $V$, but, holding $p_{M}$ constant, the probability that any given buyer buys is now raised by some $q>0$, since $p_{M}<\bar{v}$ must hold. All else equal, the gain in the expected profit of the seller is $(M-1) q p_{M}$. In turn, there exists $M_{\alpha}^{*}$ such that if $M>M_{\alpha}^{*}$, then $(M-1) q p_{M}>V$. By revealed preference, re-optimizing the price given random exclusion of a single buyer can only further raise the seller's expected profit.

Proof of Proposition 2. Let $b(v)$ be the symmetric and monotone bidding strategy with $b(0)=0$. Let's denote the payoff, maintaining equilibrium behavior by others, when type $v$ pretends to be type $z$ by $E U(v, z)$ and let $G(z)$ be the cdf of the highest intrinsic taste amongst the remaining $N-1$ active bidders. In case of a downward deviation,

$$
E U(v, z)=G(z)\left[v-b(z)+\alpha \int_{v}^{\bar{v}}(x-v) h(x) d x\right]
$$

where $H(y)$ is the cdf of the highest intrinsic taste of the excluded bidders. In turn,

$$
E U_{z}(v, z)=g(z) v-g(z) b(z)-G(z) b^{\prime}(z)+g(z) \alpha \int_{v}^{\bar{v}}(x-v) h(x) d x
$$

Implying the local optimality condition of:

$$
b(v)=\frac{1}{G(v)} \int_{0}^{v} g(x)[x+\alpha K(x)] d x
$$

where, with a slight abuse of notation, $K(x)=\int_{x}^{\bar{v}}(y-x) h(y) d y$, with $K(x) \equiv 0$ if $K=0$, is the expected mimetic dominance boost given random exclusion. To show that downward deviations are not profitable, consider $E U(v, z)-E U(v, v)$ given $z<v$. Note first that this difference can be written as:

$$
(G(z)-G(v))(v+\alpha K(v))+\int_{z}^{v} g(x)(x+\alpha K(x)) d x .
$$

Substituting terms and integrating by parts, the difference is:

$$
G(z)(v-z)+\alpha G(z)(K(v)-K(z))-\int_{z}^{v} G(x) d x+\alpha \int_{z}^{v}(1-H(x)) G(x) d x,
$$


which can be further written as

$$
(1-\alpha) G(z)(v-z)-(1-\alpha) \int_{z}^{v} G(x) d x+\alpha\left[\int_{z}^{v} G(z) H(x) d x-\int_{z}^{v} G(x) H(x) d x\right]<0,
$$

Consider now $z>v$. Here,

$$
\begin{aligned}
E U(v, z)= & G(z)(v-b(z))+ \\
& \left.\alpha \int_{v}^{z}(x-v)(g(x) H(x)+G(x) h(x)) d x+\alpha G(z) \int_{v}^{\bar{v}}(x-v) h(x) d x\right] .
\end{aligned}
$$

$E U_{z}(v, z)$, evaluated at $z=v$, we again get:

$$
E U_{z}(v, v)=g(v) v-g(v) b(v)-G(v) b^{\prime}(z)+\alpha g(v) \int_{v}^{\bar{v}}(x-v) h(x) d x .
$$

Hence, the local necessary condition for optimality is the same. Consider now the difference $E U(v, z)-E U(v, v)$ given $z>v$. Note first that this difference can be written as:

$$
\begin{aligned}
& G(z)(v-z)+\int_{v}^{z} G(x) d x-\alpha \int_{v}^{z} K(x) g(x) d x+ \\
& +\alpha\left[\int_{v}^{z}(x-v)(h(x) G(x)+H(x) g(x)) d x+\right. \\
& \left.+G(z) \int_{v}^{\bar{v}}(x-v) h(x) d x-G(v) \int_{v}^{\bar{v}}(x-v) h(x) d x\right] .
\end{aligned}
$$

Note also that $\int_{v}^{z} K(x) g(x) d x=K(z) G(z)-K(v) G(v)+\int_{v}^{z}(1-H(x)) G(x) d x$, since $K^{\prime}(x)=-(1-H(x))$. Hence, the above can be further written as:

$$
\begin{aligned}
& (1-\alpha)\left[G(z)(v-z)+\int_{v}^{z} G(x) d x\right]+ \\
& +\alpha\left[-K(z) G(z)+K(v) G(v)+\int_{v}^{z} H(x) G(x) d x+\right. \\
& +\int_{v}^{z}(x-v)(h(x) G(x)+H(x) g(x)) d x+ \\
& \left.+G(z) \int_{z}^{\bar{v}}(x-v) h(x) d x-G(v) \int_{v}^{\bar{v}}(x-v) h(x) d x-G(z)(z-v)\right] .
\end{aligned}
$$

Simplifying terms, $K(v) G(v)=G(v) \int_{v}^{\bar{v}}(x-v) h(x) d x$, and $G(z) \int_{z}^{\bar{v}}(x-v) h(x) d x=$ $G(z) K(z)+G(z)(z-v)(1-H(z))$, the part inside the second square brackets can then be written as:

$$
\begin{aligned}
& \int_{v}^{z} H(x) G(x) d x+\int_{v}^{z}(x-v)(h(x) G(x)+H(x) g(x)) d x+ \\
& +G(z)(z-v)(1-H(z))-G(z)(z-v)]
\end{aligned}
$$


which is non-positive. Hence, the overall difference is negative, and there is no incentive to deviate upwards. It follows that if $\alpha=0$, bidding is independent of $K$. Note also that for $K>0, b(v)$ can be written as

$$
v+\alpha K(v)-\int_{0}^{v} \frac{G(x)}{G(v)}[1-\alpha(1-H(x))] d x
$$

where $1-\alpha(1-H(x))>0$ which is independent of $N$. Hence, holding $K$ constant, bids are increasing in $N$. Similarly, holding $N$, constant, bids are increasing in $K$ since $K(v)$ increases in $K$ and $H(x)$ is decreasing in $K$ for any $x<1$.

Proof of Proposition 3. From the proof of Proposition 2 it follows that:

$$
\begin{aligned}
& b(v)=\frac{1}{G(v)} \int_{0}^{v} g(x)(x+\alpha K(x)) d x \\
& b(v)=(1-\alpha) \frac{N-1}{N} v+\alpha \frac{K}{K+1}+\alpha\left(1-\frac{K}{K+1}\right)\left(\frac{N-1}{K+N}\right) v^{K+1}
\end{aligned}
$$

$\Pi(M, K)$ is thus:

$$
\frac{M-K-1}{M-K+1}(1-\alpha)+\alpha \frac{K}{K+1}+\alpha\left(1-\frac{K}{K+1}\right)\left(\frac{M-K-1}{M}\right) \frac{M-K}{M+1} .
$$

Ignoring integer constraints, consider $\Pi_{K}(M, K)$. Note that $\Pi_{K}(M, K)<0$ if $\alpha=0$ and $\lim _{\alpha \rightarrow 1} \Pi_{K}(M, K)>0$, with $\Pi_{K}(M, K)$ increasing in $\alpha$ and $\Pi_{K, K}(M, K)<0$. It follows, that there exists $\alpha_{M}$ such that if $\alpha>\alpha_{M}$, then $\Pi(M, K)$ is globally increasing in $K<M-2$. Simple calculations show that $\Pi(M, 1)>\Pi(M, 0)$ iff $\alpha>\alpha^{*}$. If $\alpha>\alpha^{*}$, there then exists $K_{M, \alpha}$ such that $\Pi(M, K)>\Pi(M, 0)$ when $K \leq K_{M, \alpha}$ where $K_{M, \alpha}$ is increasing in $\alpha$. In turn, for $\alpha \in\left(\alpha^{*}, \alpha_{M}\right), \Pi(M, K)$ is inverse $U$-shaped in $K$. Finally, to show that $K_{M, \alpha}$ is increasing in $M$, note that $\operatorname{sign}\{\Pi(M, K)-\Pi(M, 0)\}=$ $\operatorname{sign}\{\alpha(1-K)+M(3 \alpha-2)\}$. In turn, if for a given $\alpha$ and $K$, this difference is positive at some $M$, it is also positive for any $M^{\prime}>M$. Corollary 5 follows from the above.

Proof of Proposition 4. Note first that under lowest exclusion, the winner of the auction is the person with the highest consumption utility. It follows from the above that, for any fixed $M$, the bidding strategy and the expected revenue under lowest exclusion and under no exclusion are the same, $\Pi(M, 0)=\Pi_{\text {Low }}(M, K)$ for any $\alpha$. Fix $M$ and $K$. Suppose that $\alpha=0$. Under random exclusion the bidding strategy is simply $b(v)=v-\int_{0}^{v}(F(x) / F(v))^{M-K-1} d x$, while under lowest exclusion it is $b_{\text {Low }}(v)=v-$ $\int_{0}^{v}(F(x) / F(v))^{M-1} d x$ 
Proof of Proposition 5. If $\alpha=0$, then $b_{i}\left(v_{i}\right)=v_{i}$, is the unique equilibrium since a person's payoff is not affected by the strategies of others. Note that for any given $p$, holding the other players' strategies constant, the payoff from obtaining the object is strictly increasing in $v_{i}$ as long as $\alpha<1$. Hence, $b_{i}\left(v_{i}\right)$ can not be decreasing in $v_{i}$ since, holding the strategies of the other players constant, this would violate incentive compatibility. Hence, $b_{i}\left(v_{i}\right)$ must be monotone increasing since the bid does not directly affect the price paid only the probability of winning. In turn, given symmetric strategies, the mimetic dominance boost can only come from the excluded ones and in equilibrium $b\left(v_{i}\right)=v_{i}+\alpha E \max _{j \in K}\left\{v_{j}-v_{i}, 0\right\}$ holds. 


\section{Appendix B: Experimental Materials}

\section{Experiment 1: Protocol (No scale)}

1. Every participant who walks in either gets a number between 1 and 12 or sits down at a lab station with a number. The bid sheets will be on their desks.

2. Participants will first read the instructions. The experimenter will read the instructions as well, and holds up the T-shirt so everyone can see it.

3. If running the Random Exclusion treatment, once everyone reads the instructions, the experimenter will announce who in the room will not be able to bid on the T-shirt. As noted in the instructions, not everyone will have the opportunity to bid on the T-shirt. The experiment will announce that "People will have the opportunity to bid on the T-shirt based on the outcome of a dice roll. I will roll a 12sided die to determine who will be not be able to bid on the T-shirt."

- If there are 4 participants, the experimenter will roll the die until one participant is eliminated. For example, if they roll a 3, the participant with the assigned number 3 cannot participate.

- If there are 6 participants, the experimenter will roll the die until two participants are eliminated. For example, if they roll a 3, the participant with the assigned number 3 cannot participate. They will then roll the die again, if they get 4 , the participant assigned number 4 cannot participate. Roll again if either there are no participants at that number or the participant with the number has already been eliminated.

- If there are 8 participants, the experimenter will roll the die until 3 participants are eliminated.

4. In the Random Exclusion treatment, the experimenter should take away the bid sheets from the participants who are eliminated.

4. In the Baseline treatment, the experimenter will announce that everyone has the opportunity to bid.

5. Everyone who can bid should then write down their bids.

6. After this the experimenter will collect the bid sheets, determine the winner, and pay everyone accordingly. Remember to do all of this discretely. Participants should be called up one at a time and given plenty of opportunity to leave the lab before the next participant is called.

7. After the experiment is over, the RAs should write down the treatment, date and time on the bids and staple them together so it will be easy to tell what data is from what session. 


\section{Experiment 1: Instructions for all treatments}

\section{Instructions}

Please enter your Lab Station Number

Today you may get the chance to participate in an auction. If you are able to participate in the auction, you will have the opportunity to use up to $\$ 15$ of the money you earned in the previous task to bid on a good. If you are selected as the highest bidder, this will be the final sale. No returns, exchanges or refunds are possible.

In the auction, you will have the opportunity to bid to win a custom T-shirt.

The custom T-shirt is designed specifically for this experiment. You cannot get this t-shirt anywhere else! The shirt is available in all sizes.

If you are given the opportunity to bid on the T-shirt, you will write down your bid on the form and wait for the experimenter to collect all of them. If you are the highest bidder, you will receive the T-shirt and your bid will be subtracted from your earnings in the previous experiment. If you are not the highest bidder, you will not get the T-shirt and nothing will be subtracted from your earnings.

If you are not given the opportunity to bid in the auction, the experimenter will collect your instructions before proceeding with the auction.

Please wait while the experimenter announces who will have the opportunity to participate in the auction. 


\section{Experiment 1: Protocol (with scale)}

1. Every participant who walks in either gets a number between 1 and 12 or sits down at a lab station with a number. The bid sheets will be on their desks.

2. Participants will first read the instructions. The experimenter will read the instructions as well, and holds up the T-shirt so everyone can see it.

3. Participants are asked to fill out the Liking Sheet. The RA collects the sheets.

4. If running the Non-Random Exclusion treatment, once everyone reads the instructions, the experimenter will announce who in the room will not be able to bid on the T-shirt. As noted in the instructions, not everyone will have the opportunity to bid on the T-shirt. The experimenter will announce that "People will have the opportunity to bid on the T-shirt based on how much they wanted to own it. Those who wanted to own it least, will not have the opportunity to bid on the T-shirt."

- If there are 4 participants, the experimenter will select the person with the lowest Liking rating and say that this lab station cannot bid on the T-shirt.

- If there are 6 participants, the experimenter will select the two people with the lowest Liking ratings and say that these lab stations cannot bid on the T-shirt.

- If there are 8 participants, the experimenter will select the three people with the lowest Liking ratings and say that these lab stations cannot bid on the T-shirt.

4. In the Non-Random Exclusion treatment, the experimenter should take away the bid sheets from the participants who are eliminated.

4. In the Baseline treatment, the experimenter will announce that everyone has the opportunity to bid.

5. Everyone who can bid should then write down their bids.

6. After this the experimenter will collect the bid sheets, determine the winner, and pay everyone accordingly. Remember to do all of this discretely. Participants should be called up one at a time and given plenty of opportunity to leave the lab before the next participant is called.

7. After the experiment is over, the RAs should write down the treatment, date and time on the bids and staple them together so it will be easy to tell what data is from what session. 


\section{Experiment 1: "Desire to own" scale}

Please enter your Lab Station Number

On a scale of 1-10, please rate the extent to which you would like to own the T-shirt (1 do not want to own to 10 very much want to own): 


\section{Experiment 2: Protocol}

1. Every participant who walks in either gets a number between 1 and 12 or sits down at a lab station with a number. Each lab station number should have a:

a. Instructions

b. Willingness to Pay Sheet

2. Participants will first read the instructions. The experimenter will read the instructions as well, and holds up the T-shirt so everyone can see it.

3. If running the Random Exclusion treatment, once everyone reads the instructions, the experimenter will announce who in the room will not be able to bid on the T-shirt. The experimenter will announce that the "People will have the opportunity to purchase the T-shirt based on the outcome of a dice roll. I will roll a 12-sided die to determine who will be not be able to purchase the T-shirt."

- If there are 4 participants, the experimenter will roll the die until one participant is eliminated. For example, if they roll a 3, the participant with the assigned number 3 cannot participate.

- If there are 6 participants, the experimenter will roll the die until two participants are eliminated. For example, if they roll a 3, the participant with the assigned number 3 cannot participate. They will then roll the die again, if they get 4 , the participant assigned number 4 cannot participate. Roll again if either there are no participants at that number or the participant with the number has already been eliminated.

- If there are 8 participants, the experimenter will roll the die until 3 participants are eliminated.

4. In the Random Exclusion treatment, the experimenter should take away the payment sheets from the participants who are eliminated.

4. In the Baseline treatment, the experimenter will announce that everyone can potentially purchase the T-shirt.

5. Everyone who can write down a willingness to pay should do so.

6. After this the experimenter will collect the payment sheets and pay everyone accordingly. Remember to do all of this discretely. Participants should be called up one at a time and given plenty of opportunity to leave the lab before the next participant is called.

7. After the experiment is over, the RAs should write down the treatment, date and time on the WTP sheets and staple them together so it will be easy to tell what data is from what session. 


\section{Experiment 2: Instructions for all treatments}

\section{Instructions}

Please enter your Lab Station Number

Today you may get the chance to purchase an item. If you are given this opportunity, you will be able to use up to $\$ 15$ of the money you earned in this experiment to purchase a good. Specifically, you will have the opportunity to purchase a custom T-shirt.

The custom t-shirt is designed specifically for this experiment. You cannot get this t-shirt anywhere else! The shirt is available in all sizes.

If you are given the opportunity to purchase the T-shirt, you will write down the maximum you would be willing to pay for it and wait for the experimenter to collect all of the forms from everyone.

To determine whether or not you will actually purchase the T-shirt, the experimenter will randomly pick a number $\mathrm{X}$ between 1 and 15 . If the number $\mathrm{X}$ is the same or smaller than the most you are willing to pay for the T-shirt, you will receive the T-shirt and $\$ \mathrm{X}$ will be subtracted from your earnings in the experiment. If the number $\mathrm{X}$ is larger than the most you are willing to pay for the T-shirt, you will not get the T-shirt and nothing will be subtracted from your earnings.

This method is used to ensure that it is in your best interest to report your true maximum willingness to pay for the shirt.

If you are not given the opportunity to purchase the shirt, the experimenter will collect your instructions before proceeding.

Please wait while the experimenter announces who will have the opportunity to purchase the shirt. 